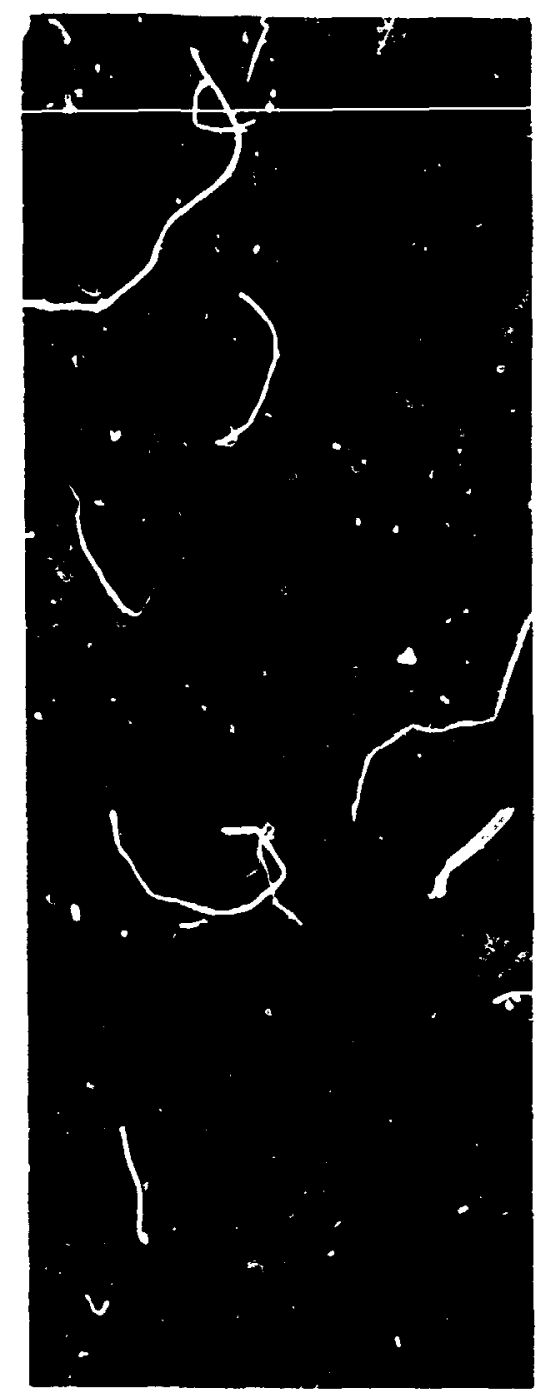

\title{
MASTER
}

\section{Gas Centrifuge Enrichment Plant Seismic Time History Development}

\author{
G. A. Aramayo \\ T G. Carley
}

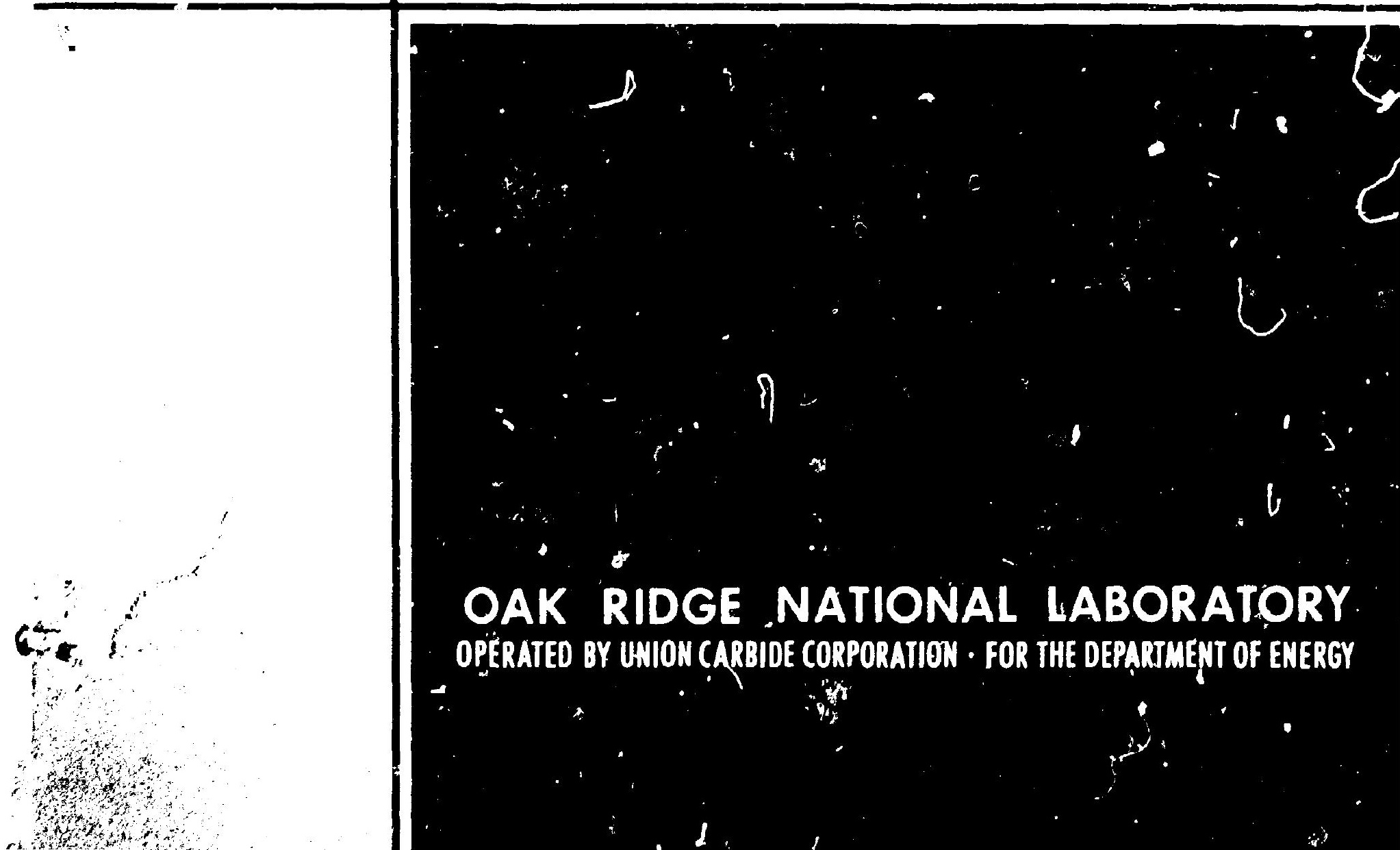


Contract No. W-7405-eng-26

ORNL Engineering Division

Gas Centrifugé Enrichment Plant

Seismic Time History Development

G. A. Aramayo

T. G. Carley

Date Publ ished - July 1979

Oak Ridge Na'-fonal Laboratory

Oak P.idge, TN 37830

Cperated By

Inion Carbide Corporation

ror the

Derartrient of Energy

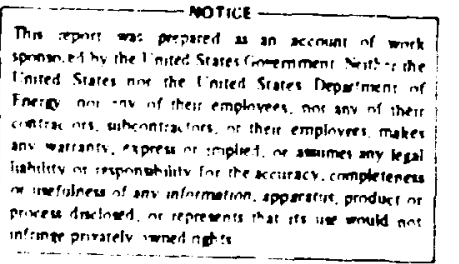


CONTENTS

List of Figures

Page

Abstract

1. INTKJDUCTION

i 1.

1

1

2. THEORETICAL BACKGROUND

3

2.1 Program ARTEQ

4

2.2 Fast Fourier Transform

6

2.3 Spectral Shaping

6

2.4 Accelerometer

7

3. INPLT

9

4. OUTPUT ACCELERDGRAMS

11

5. REFERENCES

13 


\section{LIST OF FIGURES}

Figure No.

Page

1 Program ARTEQ - Block Diagram 14

2

San Fernando Earthquake - February 9, 1971

15

3

Lower California Earthquake - November 12, 1954

16

Northern Cal ifcrnia Earthquake - September 12, 1966

17

5

Northern California Earthquake - Decembe- 18, $1967 \quad 18$

6

borrego Mountain Earthquake - Apri1 8, 1968

19

GATH.02 Accelerogram

20

GATH. 04 Accelerogram

21

9

GATH.09 Accelerogram

22

GATH. 10 Accelerogram 23

GATH. IE Accelerograa

Amplitude Frequency Spectra - GATH.02

PSV Response Spectra - GATH.02

Acceleration Response Spectra - GATH.02

Amplitude Frequency Spectra - GATH.04

28

ISV Response Spectra - GATH.04

Acceleration Response Specira - GATH.04

30

Amplitude Frequency Spectra - GATH.c9

PSV Response Spectra - GATH.09

Afceleration Response Spectra - GATH.09 33

Amplitude Frequency Spectra - GATH. 10

PSV Response Spectra - GATH. 10

Accoleration Response Spectra - GATH.10

Amplitude Frequency Spectra - GATH. 15

PSV Response Spectra - GATH. 15

GATH.02 - inceleration

GATH.02 - Velocity

GATH.02 - Displacement

GATH.04 - Acceleration 
Figure No.

32 GATH.04 - Displacement 45

33 GATH.09 - Velocity 46

34 GATH.09 - Velocity 47

35 GATH.09 - Displacement 48

36 GATH.10 - Acceleration 49

37 GATH.10 - Velocity 50

38 GATH.10 - Displacement 51

39 GATH.15 - Velocity 52

40 GATH.15 - Velocity 53

41 GATH.15 - Displacement 54

42 Normalized Cross-Correlation, GATH.02 - GATH.04 55

43 Normalized Cross-Correlation, GATH.02 - GATH.09 56

44 Normalized Cross-Correlation, GATH.02 - GATH.10 57

45 Normalized Cross-Correlation, GATH.02 - GATH.15 58

46 Normalized Cross-Correlation, GATH.04 - GATH.09 59

47 Normalized Cross-Correlation, GATH.04 - GATH.10 60

48 Normalized Cross-Ccrrelation, GATH.04 - GATH.15 61

49 Normalized Cross-Correlation, GATH.09 - GATH.10 62

50 Normalized Cross-Correlation, GATH.09 -GATH.15 63

51 Normalized Cross-Correlation, GATH.10 - GATH.15 64 


\title{
GAS CENTRIFTICE ENRICHMENT PLANT \\ SEISMIC T'ME HISTORY DEVELOPMENT
}

G. A. Aramayo

T. G. Carley

\begin{abstract}
The objective of this study is to generate a number of artificial-spectrum consistent-time histories for use in the seismic analysis of the Gas Centrifuge Enrichment Plant (GCEP) service modules (SM).

The method used in the generation of the artificial time histories presented in this report makes use of the fast Fourier transform (FFT) algorithm to modify the Fourier frequency spectrum of a recorded accelerogram. The response spectrim of the generated accelerogram is consistent with the spectrum specification given by USAEC Regulatory Güle 1.60 .
\end{abstract}

Five statistically independent time histories have been developed. These accelerograms are based on recorded West Coast accelerations that meet specif ic requirements associated with the location of the recording station with regard to the epicenter. The acceleration time history, Fourier and response spectras, and integrated velocity and displacement records are presented.

\section{INTRODUCTION}

The objective of this study is to generate a number of artificial, spectrum-corsistent, time histories for use in the seismic analysis of the Gas Centrifuge Enrichment Plant (GCEP) Service Modules.

The methodology associated with the development of artificialspectrum consistert-time histories that meet the requirements stipulated per Y/EN 204, " "Seisnic Design Criteria for the Gas Centrifuge Enrichment Plant - GCEP," is presented herein. This report meets the requirements of Task IV of the Engineering Analysis Department (EA) Support to $\mathrm{Y}-12$ Civil and Architectural Engineering (YCA) service modile design. ${ }^{2}$ 
The method used in the development of the time histories uses the fast Fourier transform (FFT) algorithm to modify the frequency spectrum of a recorded earthquake to produce an accelerogram with a response spectrum that envelops the U. S. Atomic Energy Commission (USAEC) Regulatory Guide $1.60^{3}$ spectra.

A general description of the mathematical foundation of the program ARTEQ ised in the generation of the artificial time histories is given in Section 2. The description of the input data used as the base for the generated acceierograms is included in Section 3. The synthesized accelerograms which meet the requirements of Task $I^{2}$ of the EA Support to YCA SM Design are shown in Section 4. The plots of the time history, pseudo velocity spectra (PVS), and acceleration response spectra, with the Regulatory Guide 1.60 spectrum superimposed in the same plot, are given in the latter part of th: $r \in$ port. 


\section{THEORETICAL BACKGROUND}

A number of approaches have been employed to generate earth motion time histories which have response spectra of a given nature. Tsai ${ }^{4}$ used a method in which the initial ground motion time history is directly modified, based on the difference between the response spectrum and the design spectrum. Response spectrum suppression was accomplished by passing the time history through a series of filters whose parameters were optimized to give the desired suppression and band width. The raising of the response spectrum was accomplished by adding sinusoidal motions to the time history, with the amplitude and phase determined by the design and response specrra difference and the time of maximum response. Rizzo et al. 5 used a method in which the modif ications to the ground motion were made by adjusting the Fourier spectrum of the ground motion time history. Response-spectrum suppression was applied directly to the Fourier spectrum in the frequency bands surrounding the responsespectrum frequency at which the response spectrum was to be decreased. The spectrum raising was accomplished by adding to the Fourier spectrum the frequency spectrum of a damped sinusoid with frequency equal to that of the point on the response spectrum at which the stectrum increase was desired.

Levy and Wilkinson ${ }^{6}$ employ a superposition of sinusoids with alternating algebraic sign upon which is impressed an enveloping function of time. The minimum response-spectrum-frequency interval is specified which causes overlapping, of the half-power points of the responses of adjacent oscillator to the sinusoidal excitations. Since the frequencies are not harmonically related, convergence does not increase beyond a certain spacing, implying an apparent optimum interval.

$\mathrm{Kaul}^{7}$ has developed a procedure in which the difference between the design and computed response spectrum is related directly to the requitred change in time history, through a response integral. This iterative process converges to the acceierogram whose response spectrum is consistent with the design spectrum. Other approashes to the problem of generating spectrum-compatible time histories include the method 
presented by Scanlan and $\mathrm{Sacus}^{8}$ in which the ground motion is synthesized by adding togather a number of randomiy phased silusoids with amplitudes aijusted to give the desired response spectra.

The method used in the generation of the artificial time histories presented in Lisis report makes use of the FFT algorithm to modify the Fourier frequency spectrum of a recorded earthquake accele:ogram. This methodology has been implemented in the digital program ARTEQ that is described in the next section.

\subsection{Program ARTEQ}

Program ARTEQ implements a Fourier frequency spectra-shaping scheme in the development of artificial, spectrum-consistent, time-history accelerograms. This progiam is implemented in Fortran compatible with the compilers in use at the lak Ridge National Laboratory (ORNL) computing facility. The progran is operational on either the IBM 360/91 or the $360 / 75$ computers.

Input environment to ARTEQ consists of punched cards (logic unit 5) and urlabeled, 9-track, $800 \mathrm{BP}$ L tape on logic unit 8. Normally, the cards are used for input of control information and the tape contains the input accelerogram that is used as a basis for the generation of the out sut accelerogram.

Program ARTEQ Implements a spectral-shaping scheme that operates on the Fourier spectra of the input accelerogram. These Fourier spectra are computed using the FFT algorithm. The magnitude of the changes to the Fouzier zequency spectra are based on the difference that exists between the response spectra of the accelerogram and the target or design spectra which is specified normally by Regulatory Guide 1.60 .

The response spectra of the accelerogram are computed for each of 200 discrete frequency points, also using the FFT algerithm. The response at each of the frequency points is calculated by multiplying in the frequency domain, the forward transform of the excitation, and the transfer func:ion of a single degree of freedom-damped oscillator. It 
should be noted that multiplication in the frequency domain is equivalent to convolution in the time domain.

In the developmen: to the response spectra, the frequency spacing in cycles/second is as follows: the first 45 points are spaced at $0.05-\mathrm{Hz}$ in ervals, the next 20 points at $0.10-\mathrm{Hz}$, and the remaining 134 points at $0.20-\mathrm{Hz}$. The lowest frequency considered is equal to $0.10 \mathrm{~Hz}$, and the highest frequency point is equal to $31.2 \mathrm{~Hz}$.

Adjustments to the Fourier frequency spectra are made to either lower or raise the calculated response spectra with respect to the specified value. These adjustments are made for each of the 200 points that form the response spectra. Once ail the frequency points are adjusted, the invarse transform yields the time history that corresponds tu the modified fourier spectrum. The process is repeated until the number of iterations requested is completed. The program does not have a specific convergence criteria that must be met. Convergence is subjective and based on the inspection of the output response spectra.

Program ARTEQ contains logic that permits the user to shape a general envelope that contains the output time history. This shaping may be required to confine the region of strong motion of the event to a specified region on the time scale of the accelerogram. This program also includes logic associated with baseline correction so that final values of the integrated acceleration record (velocity and displacement) can be controlled.

Figure 1 presents a block diagram of the steps involved in the generation of the required time history. The steps associared with instrumert and baseline correction and interpolation of the raw data, that are discussed in a latter section, are external to the program ARTEQ logic. These steps are not required components of the computational procedure of ARTEQ. 


\subsection{Fast Fourier Transform}

Th.? fast Fourier transform (FFT) computational algorithn is used for the determination of the response and frequency spectrum of the accelerograms.

The FFT algorithm is implemented in Fortran in the subroutine FoUR2. This package codes the Cooley-Tukey fast Fourier transform algorithm for the calculation of the discrete Fourier transform of finite input accelerograms.

The FFT algorithm is restricted to operate on a time series specified by a total number of points that is a power of two. The resolution in the frequency domain as well as the frequency content of the time series are limited by the sampling rate of the input data.

The relationship between the time-sampling rate, $\Delta t$, the number of points of the time series, $N$, and the spacing of two consecutive points in the frequency domain is given by the expression:

$$
\Delta \omega=\frac{2 \pi}{N \Delta t} \text {. }
$$

On1y $\mathrm{N} / 2$ unique frequency points are generated, the highest of these points is the "folding" or Nyquist frequency and is equal to $\omega_{n}=\pi / \Delta t$. This frequency is significant in that any energy present in the data with a frequency above $\omega_{n}$ will appear erroneously at a lower frequency.

\subsection{Spectra Shaping}

The Fourier frequency spectra of the input accelerogram are initially band-pass-filtered between $0.7 \mathrm{~Hz}$ and $25.0 \mathrm{~Hz}$. The upper cut-of $f$ frequency is equal to the Nyquist frequency when the time sampling rate is equal to $0.02 \mathrm{sec}$, so that problems associated with aliasing are eliminated.

The objective of the program is achieved by modifications of the filtered Fourier frequency spectra, using the comparison between the magnitudes of the acceleration-response spectra and the design spectra 
specified by USAEC Reg. Guide 1.60 as a reference fur the magnitude of correction and location at which frequency the modifications are to be made.

If at a particular frequency the response-spectrum vaiue is above the design-spectrum value, the Fourier spectrum amplitude is decreased in a relatively narrow frequency band by an amount proportional to the ratio of the response to tile design value. The modified bandwidth includes one trequency point imnediately above and immediately below the frequency point under consideration. The number of modified components of the Fourier spectrum is limited so that only one responsespectrum trequency is modified at a given time. The narrower the band of frequencies modified, the more detailed modifications to the response frequency are realizable.

If the response spectrum is less than the design-spectrum value at a particular frequency point, the Fourier frequency spectrum is modified by adding the Fourier spectrum of a damped sinusoid to the spectral components at the corresponding frequency point. The magaicude of the damping factor of the sinusoid is equal to 0.0064 . This damping factor is associated with a logarithm decrement of 0.04 (the ratio of the amplitudes of two successive cycles is 0.04 ).

The phase angle of the added sinisoid is shifted so that the maximum response due to tine sinusoidal exci:ation occurs at tire same time that the maximum value accurred for the response-spectrum point under consideration.

\subsection{Accelerogram Shaping}

For the iteration just completed, the inverse transform of the m. $d$ ified Fourier spectra provides an acceleration history. Before going into the next iteration, the accelerogram is modified so that the maximum peak values do not exceed the prescribed maximum acceleration, and alsu the entire accelercgram is modified so that it fit:; an envelop which is believed to represent the typical characteristic of a rescrded earthquake acceleration. 
This cosmetic envelope is intended to confine the strong wotion activity to the time interval beyond the $4 \mathrm{sec}$ after initiation of the event. There is an expor ential buildup in this interval so that the magnitude of the initial acceleration cannot exceed $8 \%$ of the maximum value in the strong motion region. This low amplitide acceleration zegion corresponds to that part of the event dominated by $P$-wave activity. Beyond the $4.0 \mathrm{sec}$, the event is characterize? by strong activity assoclated with S-wave-type excitation.

In general, the latter portion of the accelerogram decays so that the vaximum amplitude in this time portion of the accelerogram is in the order of $20 \%$ of the zero-period acceleration, this being the threshold that defines the duration of the earthquake as specified by Ref. 2 .

The shaping of the output time histories is the input to the next iteration that computes a new response spectrum used in this interaction cycle. 


\section{IRPUT DATA}

In the process of generating an accelerogram which has a response spectra that envelops the design spectra spe:cified by USAEC Regulatory Guide 1.60, program ARTEQ has the capability to initiate the iteration procedures, using as a basis the calculated response spectra of white noise or the response spectrum of a recorded or artificially generated acceleroyram. In the current study, the input is given by the time history of a recorded acceleration of one of several West Coast earthquakes.

The input time series represent the corrected accelerograms that have compensation for instrument and baseline discrepancies ${ }^{9}$ in Fig. 1. These data are based on uncorrected accelerograms hand-digitized at unequally spacr intervals. The scheme used in the interpolation and correction of the input lata is not a part of ARTEQ. This cor-ection, performed externally to and before the input to ARTEQ, is described as follows: Equally spaced data with 50 points per second are interpolated from the raw data source. The interpolation is based on the following scheme: the first 100 equally spaced points per second are obtained from the uncorrected data, the equally spaced data are then low-passfiltered with a cut-of f frequency equal to $25 \mathrm{~Hz}$ (roll-off termination at $27.0 \mathrm{kz})$. Next, every other point is eliminated, leaving a time series with 50 points per second that corresponds to a Nyquist frequency of $25.0 \mathrm{~Hz}$.

Instrument correction is based on the integration of the response data of a single-degree-of-freedom (SDOF) oscillator where the excitation is the filtered accelerogram described in the previous paragraph. The damping ratio and natural frequency of the oscillator are determined from calibration tests of the recording instrument.

Baseline correction is effected by high-pass-filtering the data with a cut-off frequency of $0.05 \mathrm{~Hz}$ (roll-off termination of $0.07 \mathrm{~Hz}$ ). The resulting histogram is claimed to represent the absolute acceleration with a frequency band between $0.07 \mathrm{~Hz}$ anc $25.0 \mathrm{~Hz}$. 
The input accelerograms are then the corrected data of measured main events (not aftershosk events) where the recording station is at a distance of 200 to $250 \mathrm{miles}(322-402 \mathrm{~km})$ from the event epicenter. The recording iostrument is located in the basement or low-floor level of light-weight buildings.

Five accelerograms have been used in the generation of the desired ime histories. These accelerograms are shown in Figs. 2 through 6. The following is the information associated with these data:

- Accelerogram No. 1 corresponds to Record No. 173 of Tape No. X18862. This event is the February 9, 1971, San Fernando earthquake. The recording station is located in the subbasement of huilding at $1150 \mathrm{~s}$. Hil1 St., Los Angeles, California.

- Acceler ugram No. 2 corresponds to Record No. 170 of Tape No. X18863. This event is the November 12, 1954, lower California earthquake. The recording station is located at ground level at E1 Centro, Imperfal Valley Irrigation District.

- Accelerogram No. 3 correspunds to Record No. 300 of Tape No. X18863. This event is the September 12, 1966, northern California earthquake. The recording station is located in the basement of the Pacific Telephone and Telegraph Building, Sacranento, California.

- Accelerogram No. 4 correspnnds to Record No. 242 of Tape No. X18863. This event in the December 18, 1967, northern California earthquake. The recording station is located at ground level in the Public Library in Hollister, California.

- Accelerogram No. 5 corresponds to Record No. 331 of Tape No. X18863. This event is the April 8, 1968, Borrego Mountain earthquake. The recording station is at ground level at the Southern California Edison Co. Bullding in Colton, California. 


\section{OUTPUT ACCELERATIONS}

The results of this study are given in the form of accelerograms that meet with the specified objectives set for the study. The rime histories developed have response spectra that envelop the response spectra given by USAEC Regulatory Guide 1.60 for the same damping constant. The duration of the event conforms with the specifications outlined in Ref. 1 .

The plots of the developed spectra-consistent accelerograms normalized to a maximum zero-period ground acceleration of $1 \mathrm{~g}$ are given in Figs. 7 through 11. Each of these accelerograms is based independently on a particular input accelerogram described in the previous section and shown in Figs. 2 through 6 . The correspondence between the input and output accelerograms is as follows:

- GATH.02 (Fig. 7) generated from input accelerogram No. 1 (Fig. 2)

- GATH.04 (Fig. 8) generated from input accelerogram No. 2 (Fig. 3)

- GATH.09 (Fig. 9) generated from input accelerogram No. 3 (Fig. 4)

- GATH.10 (Fig. 10) generated from input accelerogram No. 4 (Fig. 5)

- GATH.15 (Fig. 11) generated from inpitt accelerogram No. 5 (Fig. 6)

The amplitude (modulus) of the Fourier frequency sfectra and the PSV and acceleration response spectra of each of the output accelerograms are shown in Figs. 12 through 26. The response-spectra plots shown correspond to the response of the SDOF oscillator with a damping factor (ratio to critical) equal to $2 \%$. The zero-period acceleration is equal to $1 \mathrm{~g}$. These plots also show the smocthed design spectra that correspond to those specifted in Regulatory Cidide 1.60 .

The GCEP criterial specify chat the duration of the operating-level earthquake (OE) should be at least equal to $20 \mathrm{sec}$. The developed time histories have durations of $40.96 \mathrm{sec}$; it h:s seen show that the first $20 \mathrm{sec}$ of these accelerations have response spectra thai satisfy the requirements, and that the magnitude $n f$ the acceleration at the enit of the time history complies with the requirements of Ref. 1 .

The generated acceleration, velocity, and displacement for each of the output accelerograms are shown in Figs. 7 through 41 . It can be 
observed that the integrated displacement shows some divergence from the baseline. The reason for this behavior can be attributed mainly to the long-reriod errors (in the displacement records) that result from small errors in the initial values as discussed in Ref. 9. It can alsu be shown that the full length of the accelerogiam is not necessarily basecorrected when only a portion (the first $40.96 \mathrm{sec}$ ) of the record are used in the input to ARTEQ. This program contains logic to filter out (via a digital high-piss filter) the effects of long-period drift during the process of generating the required accelerogram, but it does not control final values for the integrated displacement. Final values f:r the velocity record can be controlled by adequate wanipulation of the Fourier components associated with the steady-state (DC) contribution to the acceleration record.

In an attempt $t$ : determine the statistica!. independence (cr Jependence) of the data generated, the cruss-correlation cuefficients between each of the output records have been computed and presented in plot form in Figs. 42 through 51.

For complete statistical independence, the cross-cnrrelation coefficient for any time lag should be equal to zero. Conversely, the cross-correlation coefificient of 1.0 implies that the two functions used in the calculations are statistically depends:-t.

There is not an established vaiue $f_{\text {. }}$ the normalized crosscorrelation coefficient between two time series that indicates that these functions are statistically independent. If the two separate records are used simultaneously for a two-axes excitation of a structure, the value of 0.16 or less indicates that these functions are statistically Independent for tinis case of excitation. 10

The correlation analysis shows that the largest cross-correlation coefficient that exists betweer. any two of the calculated ilistograms does not exceed the value of 0.25 . It is antictpated that this low correlation coeffictent implies that there 1s little statistical dependency between any two of the deveioped accelerograms. 


\section{REFERENCES}

1. J. E. Beavers, "Seismic Design Criterfa for the Gas Centrituge Enrichment Plant - GCEP," UCC-ND _ngineering Division, Y/EN-204, August 1978.

2. Internal communication, J. E. Beavers to W. C. T. Stoddart, "GCEP Service Module," September", i978.

3. U. S. Atomic Energy Commission, Directorate of Regulatory Standards, Regulatory Guide 1.60, "Design Response Spectra for Seismic Design of Nuclear Power Plants," December !973.

4. N. C. Tsai, "Spectrum Compatible Mntions for Design Purposes," ASCE J. Eng. Mech. Div., Vol. 98, No. E:2, Paper No. 8807, pp. 345-356, Arril 1972.

5. P. C. Rizzo, D. E. Shaw, and S. J. Jarecki, "Development of Real! Synthetic Time Hiszories to March Smooth Design Spectra," Proceedings, Second International Conference on Structural Mechanics in Reactor Technology, Vol. 4, Part K, Paper K 1/5, Berlin, West Germany, September 1973.

6. S. Levy and J. P. D. Wilkinson, "Generation of Artificial TimeHistorles, Rich in All Frequencies, From Given Response Spectra," Niscl. Eng., Vo?. 38, No. 2, pp. 241-251, August 1976.

7. M. K. Kaul, "Spectrum-Consistent Time-History Generation," ASCF J. Eng. Mech. Div., Vol. 104, No. EM4, pp. 781-788, August 1978.

8. R. I. Scanlan and K. Sachs, "Earthquake Time Histories and Response Spectra," ASCE J. Eng. Mech. Div., Vol. 100, No. EM4, Paper No. 10703, pp. 635-i55, August 1974.

9. California Irstitute of Technology - Earthquake Engineering Research Laboratory, "Strong-Motion Earthquake Accelerograms Digitized and Plotted Data, Volume IT - Corrected Accelerograms and Integrated Ground Velocity and Displacement Curves - Part A - Accelerograms IIA001 through IIA020," EERL 71-50, September 1971.

10. Chen Chang, "Definition of Statistically Independent Time Histories," ASCE J. Struct. Div., Tech. Note, Vol. 101, No. ST2, pp. 449-451, February 1975. 
ORNL-DWG 79.120 .7

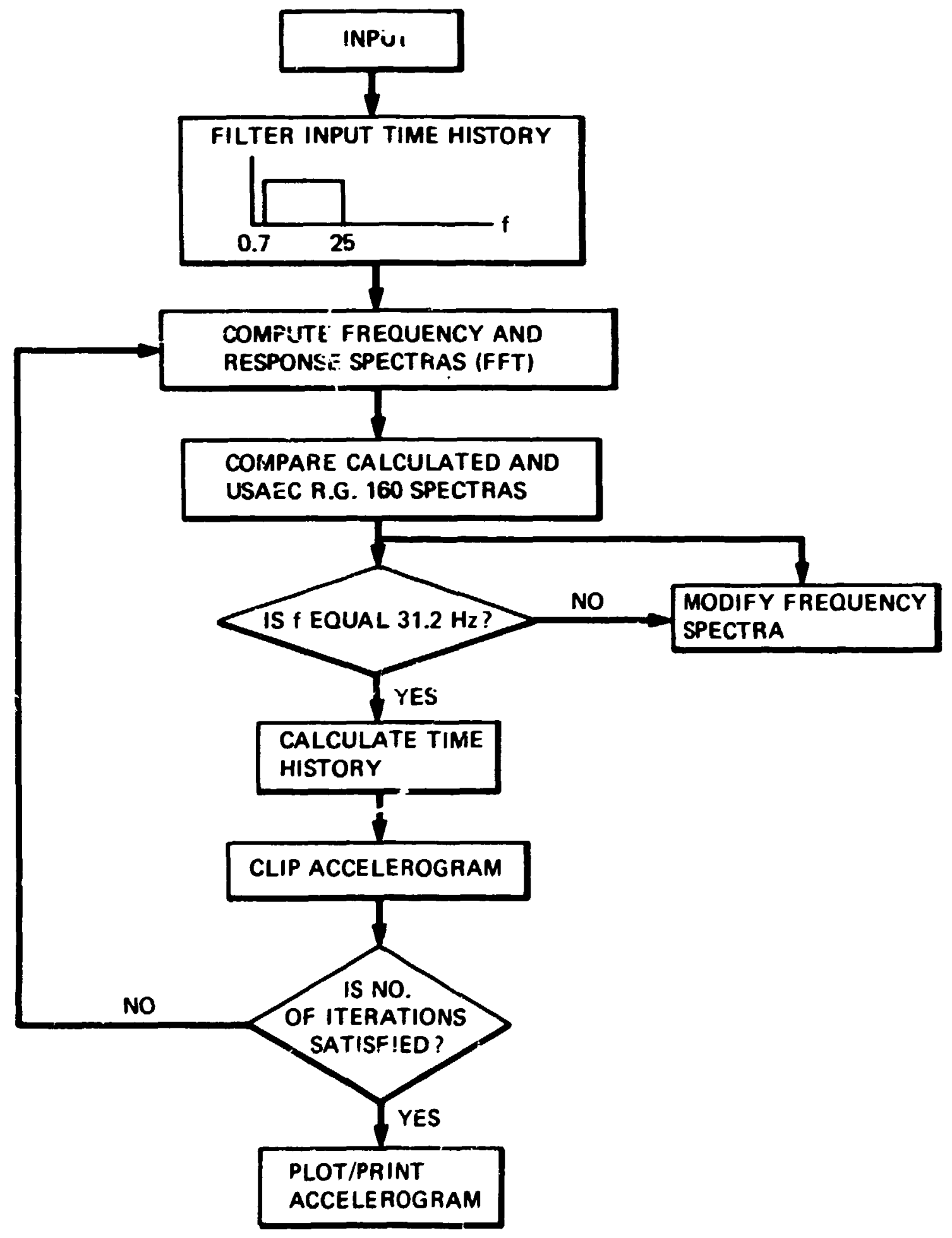

Fig. 1. Program ARTEQ - Block Dlagram. 


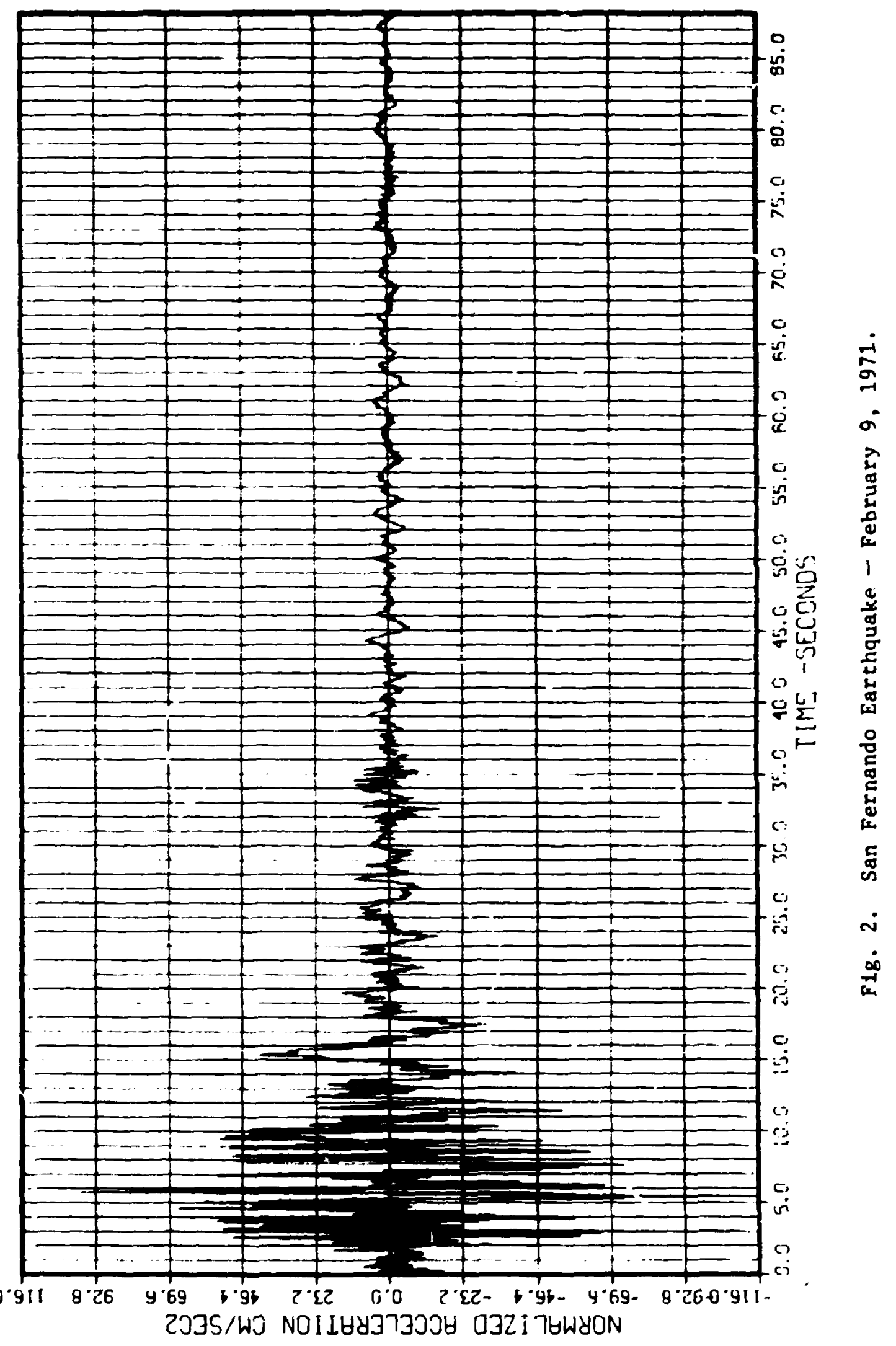




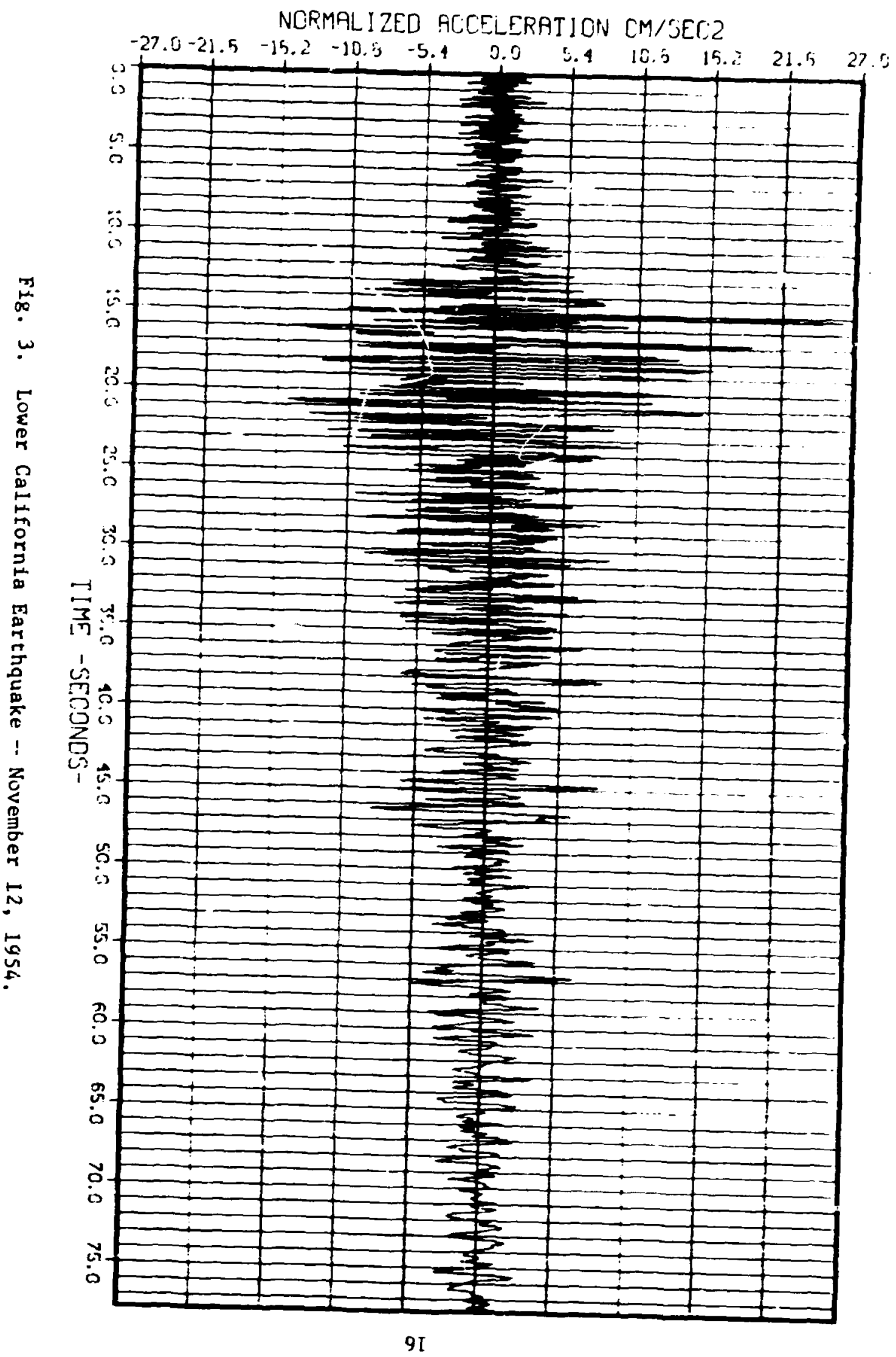




\section{7}

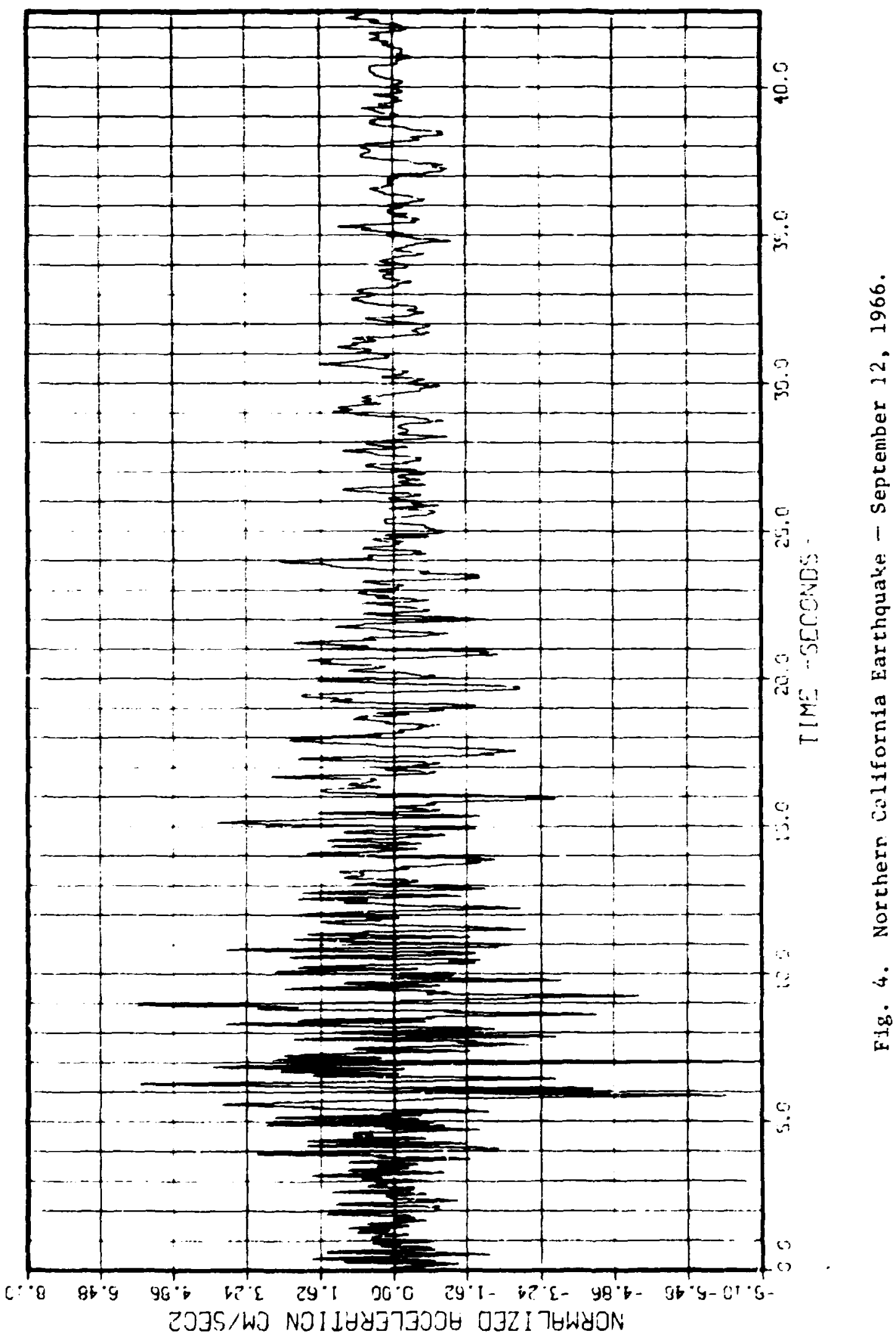



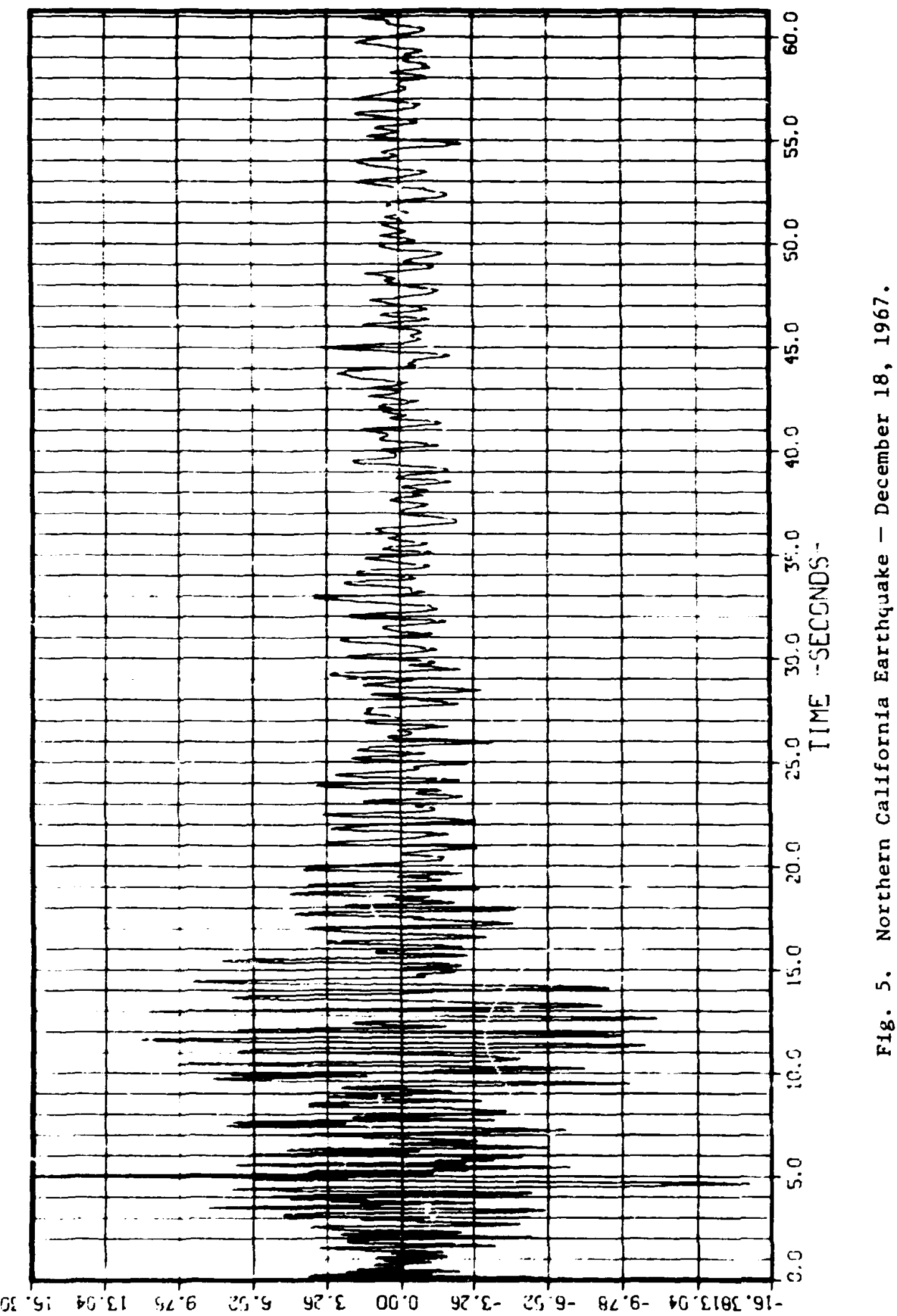

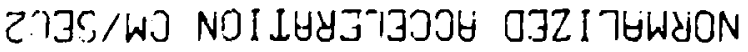




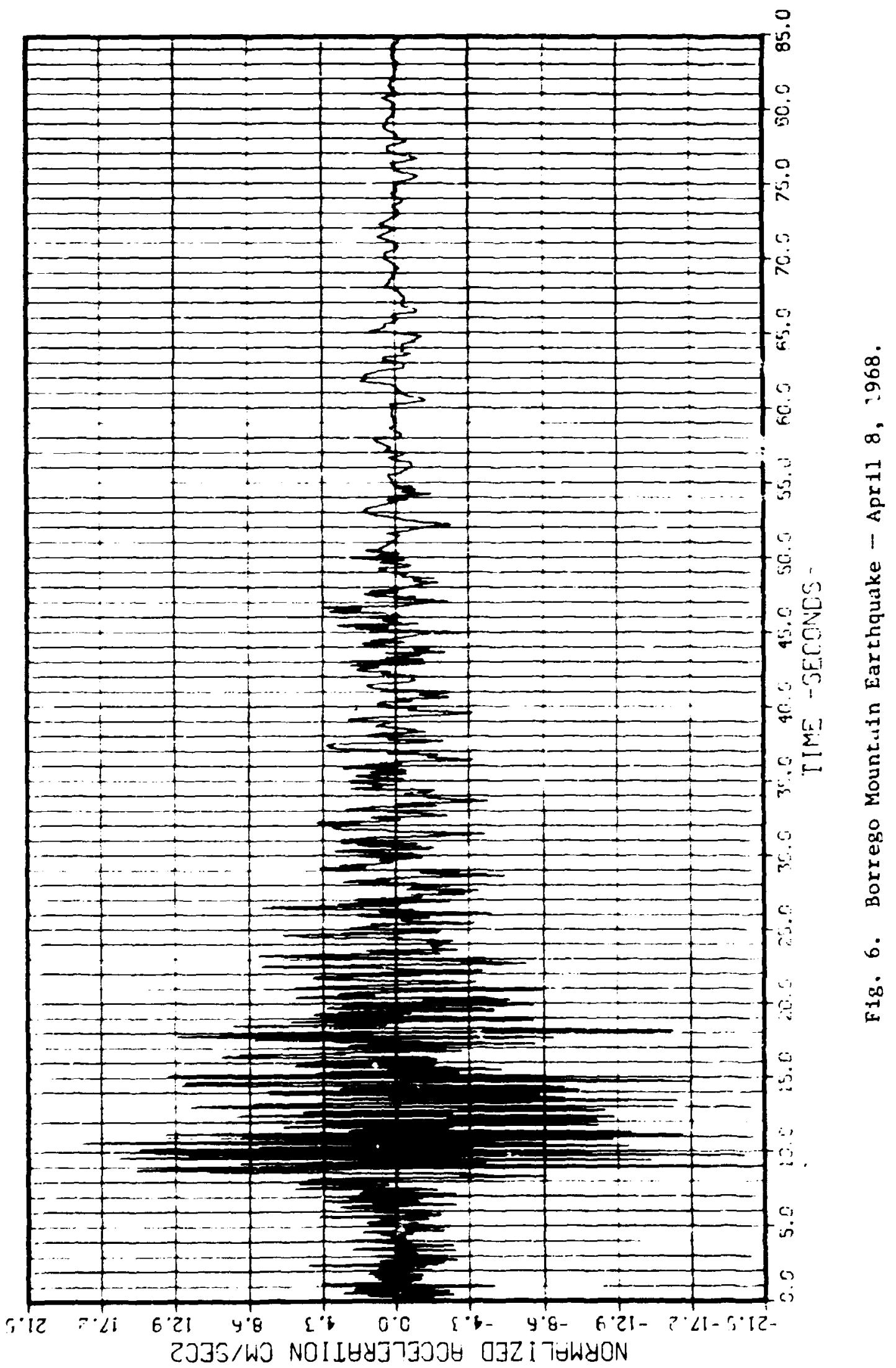




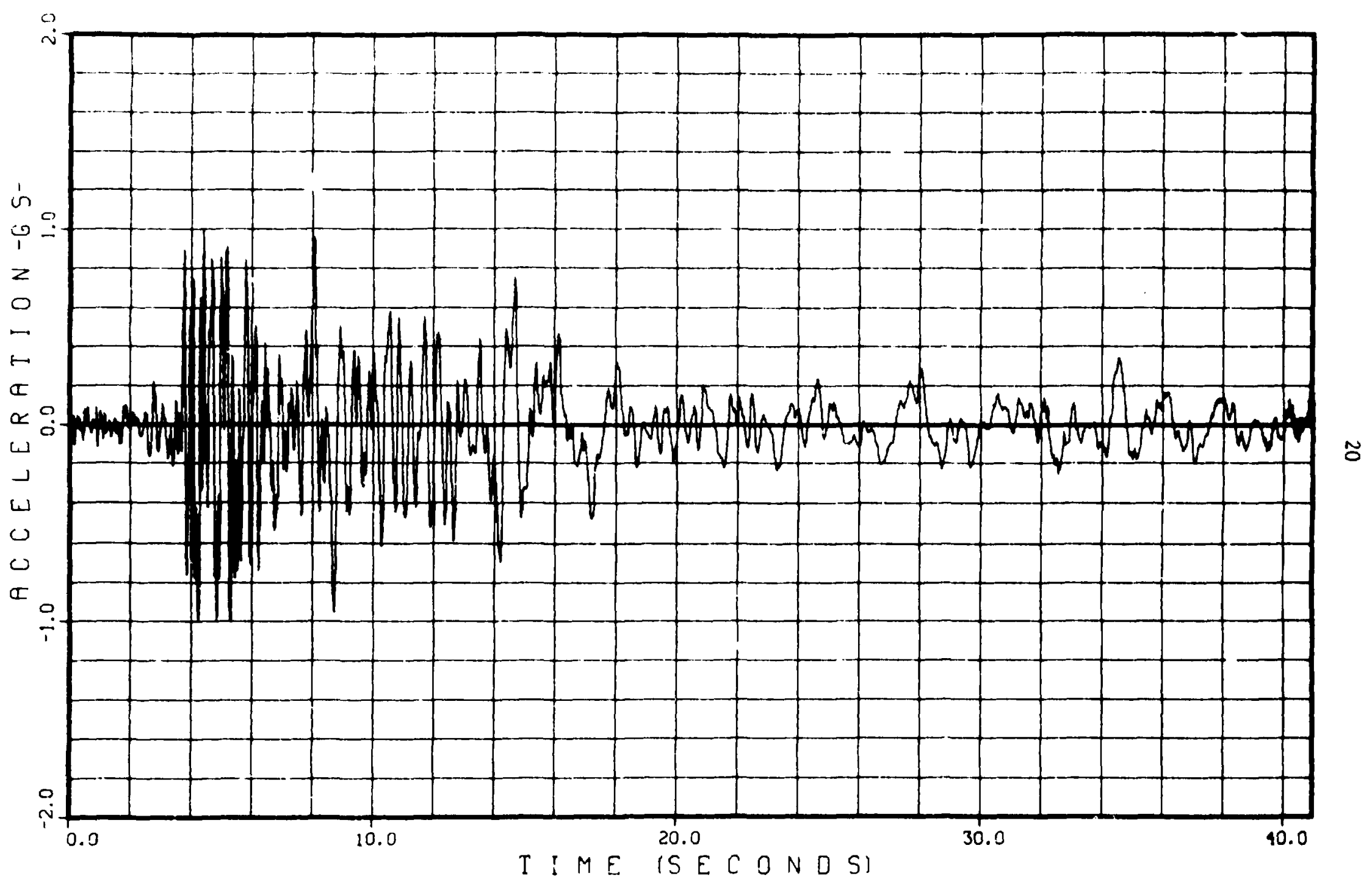

Fig. 7. GATH.02 Accelerogram. 
21

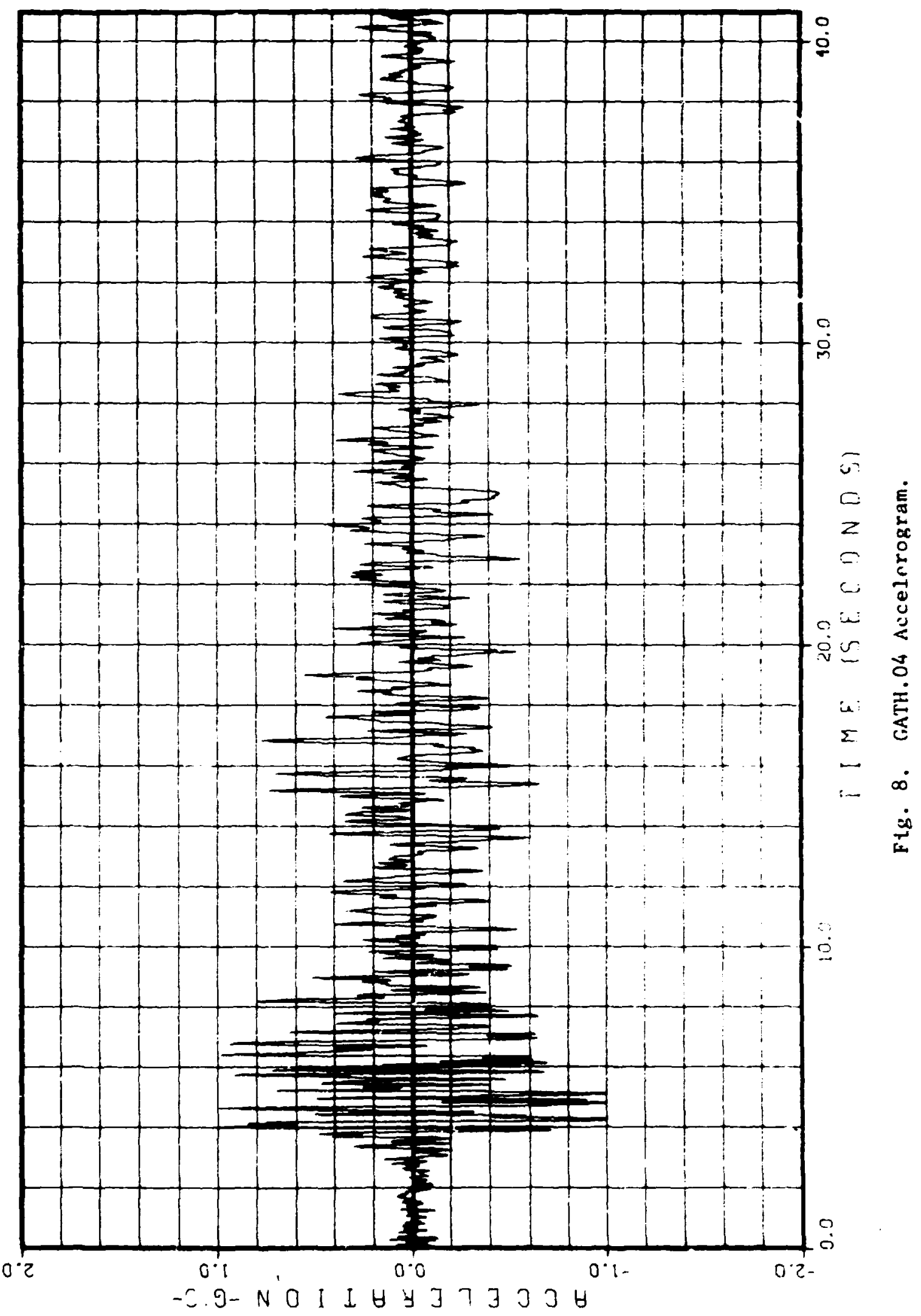




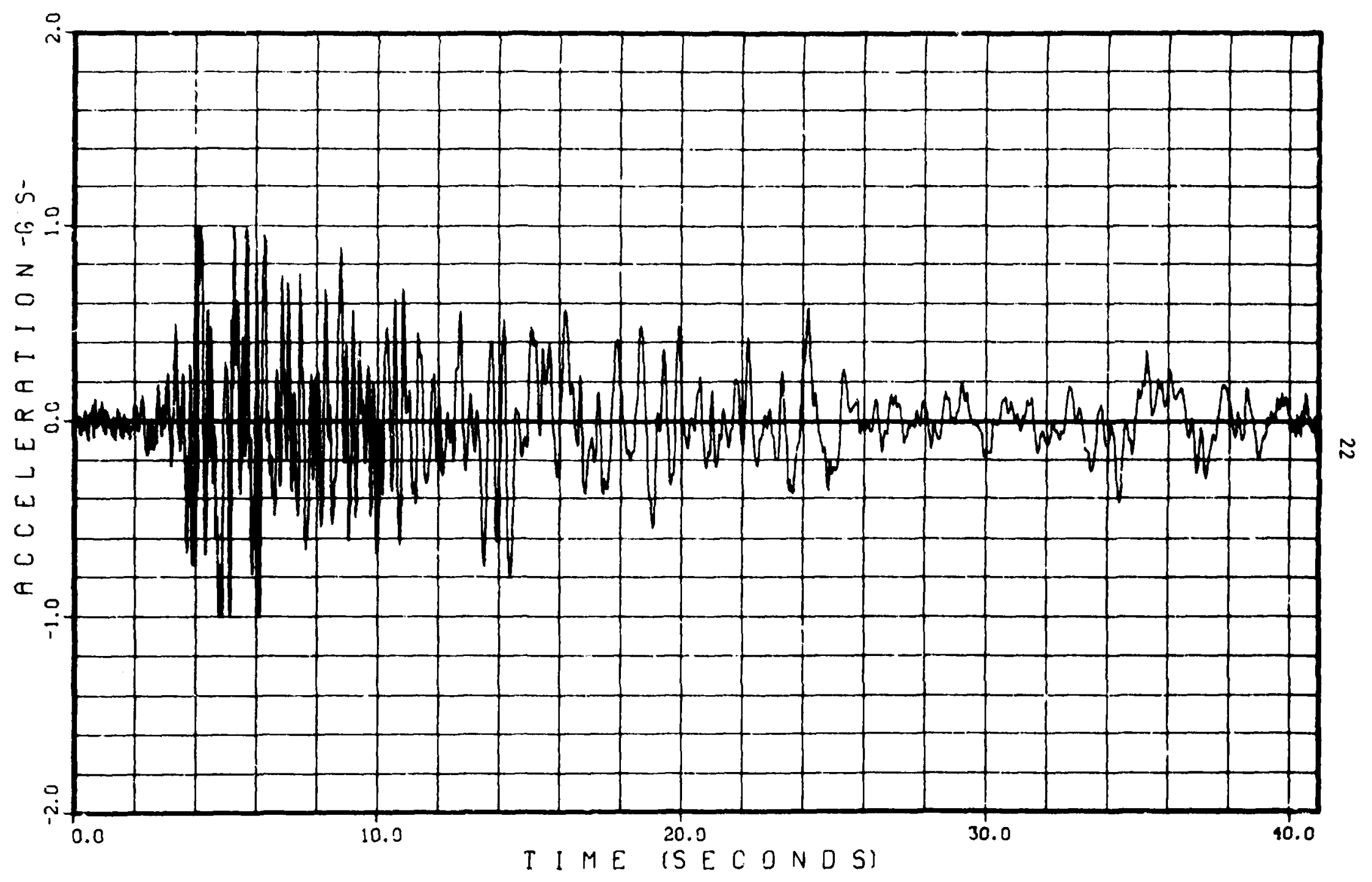

Fig. 9. GATH.09 Accelerogram. 


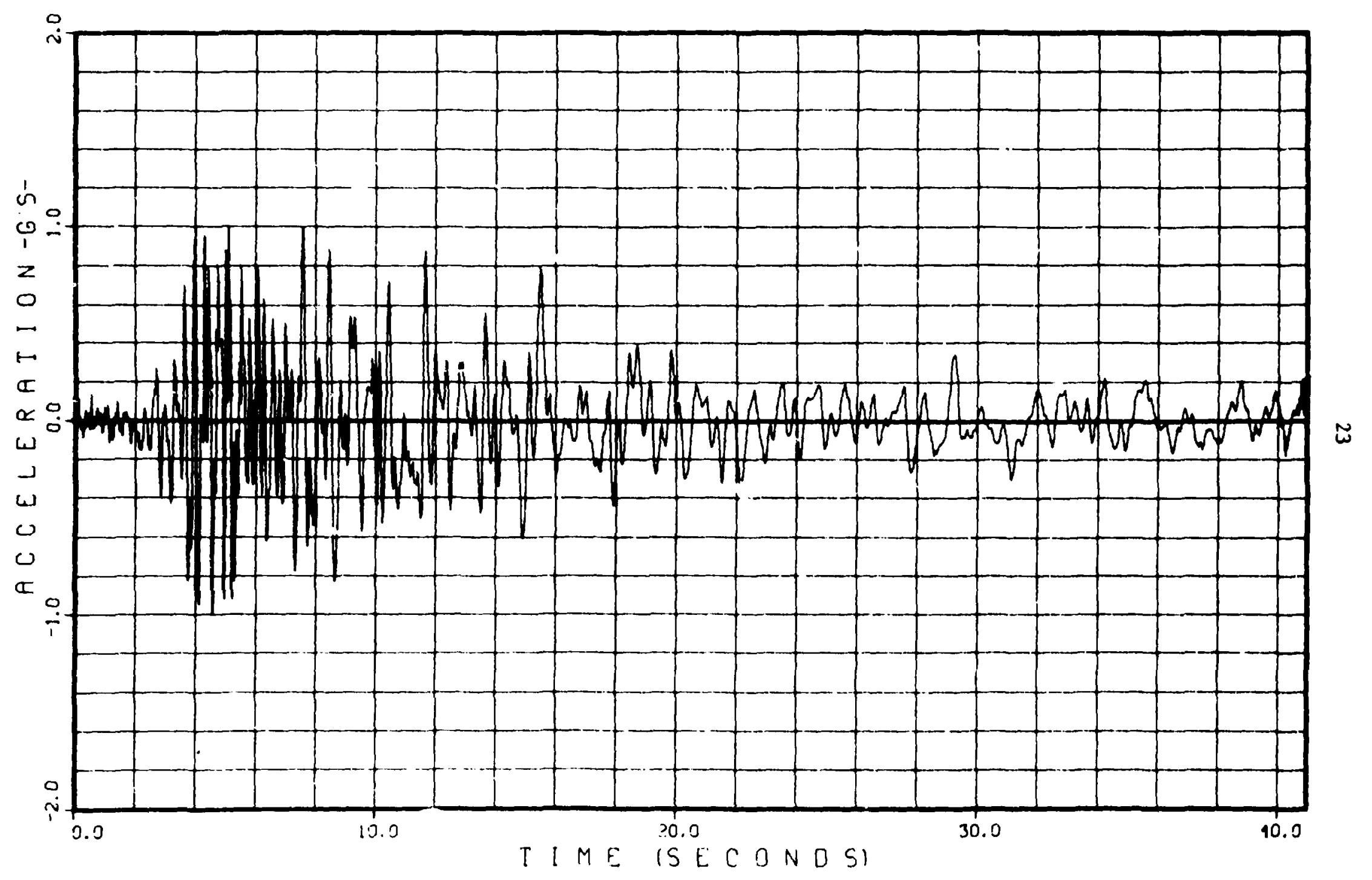

F1g. 10. GATH.10 Accelerogram. 


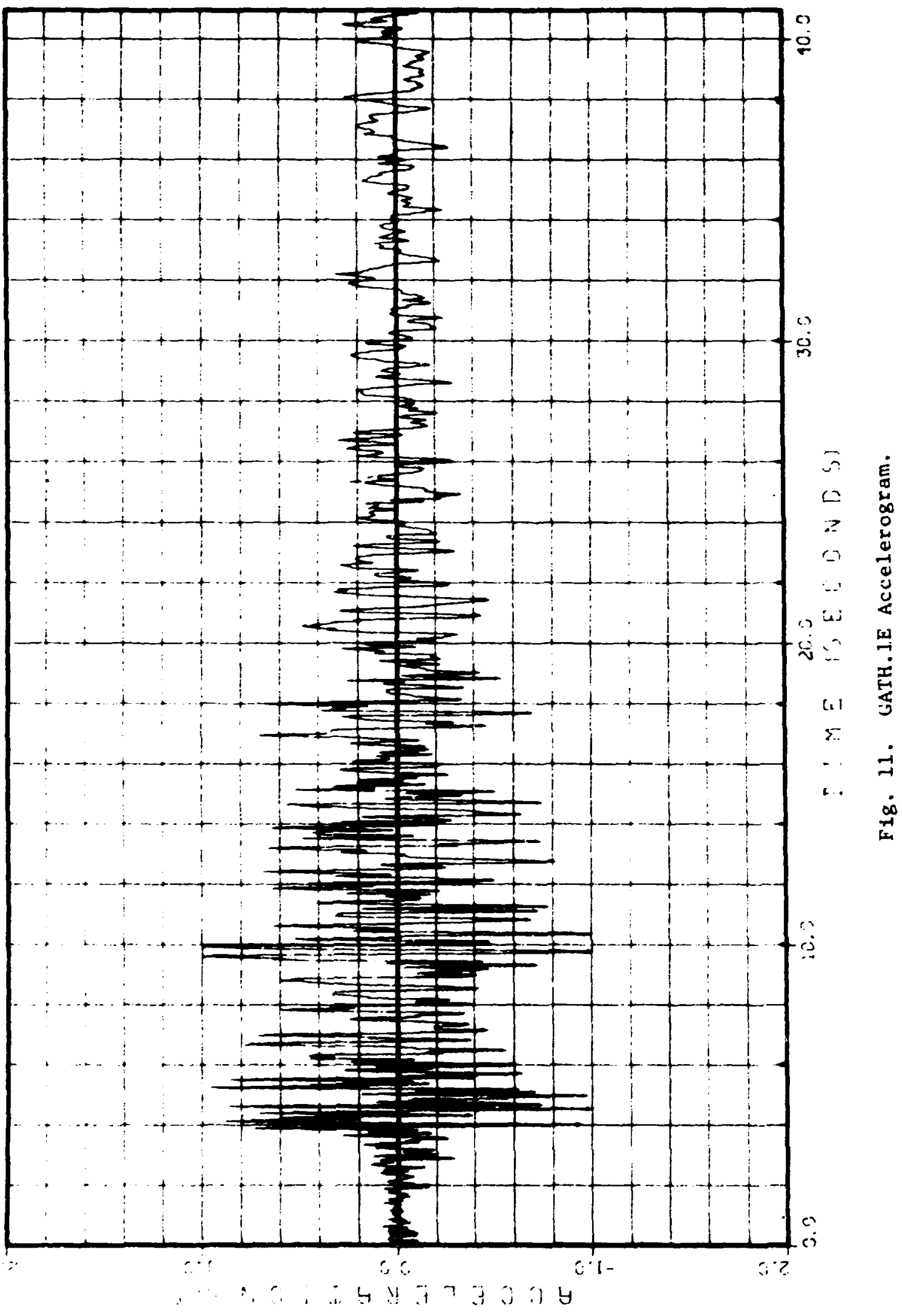


FREOUENCY SPECTRUM

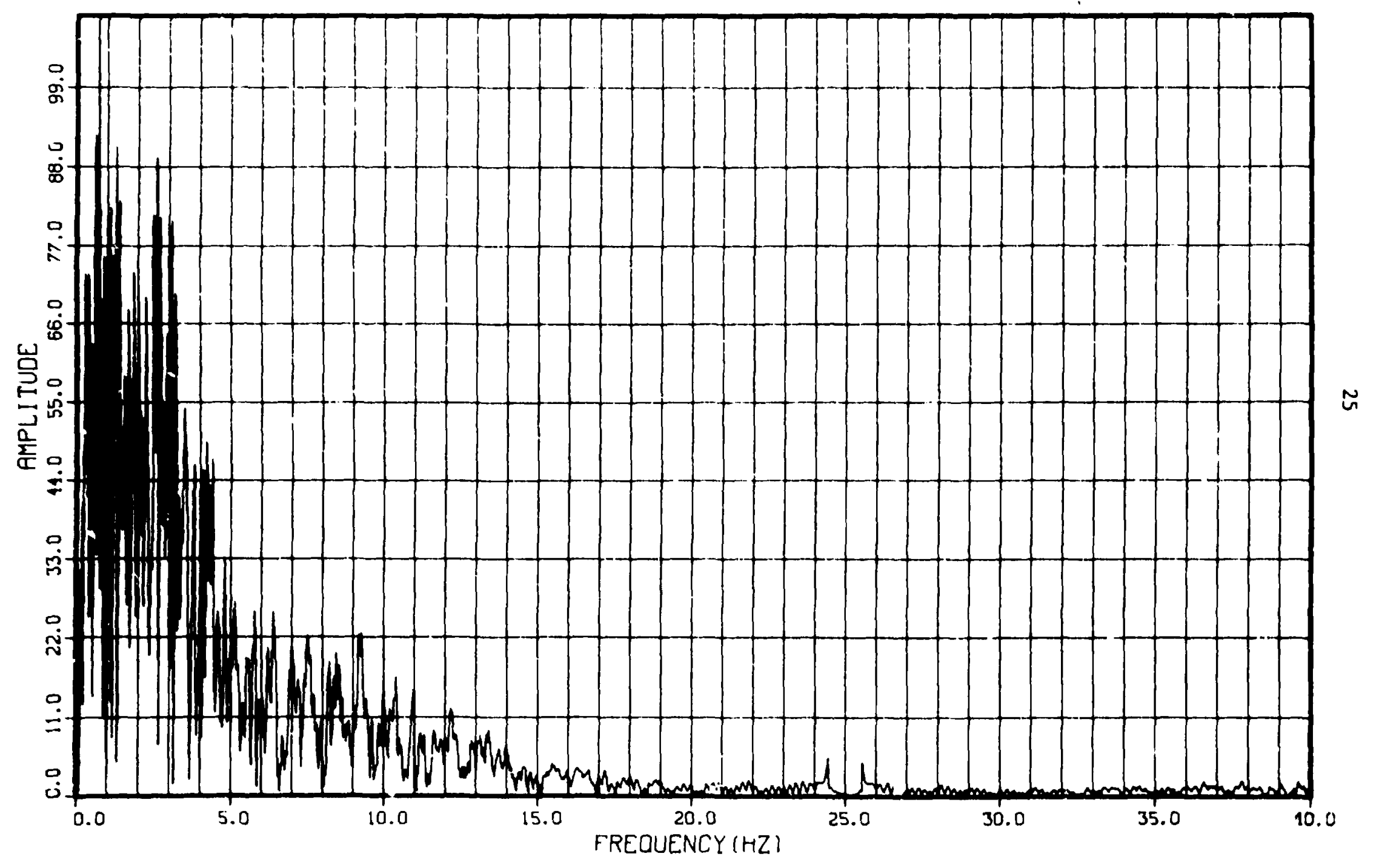

Fig. 12. Amplitude Frequency Spectra - GATH.02. 


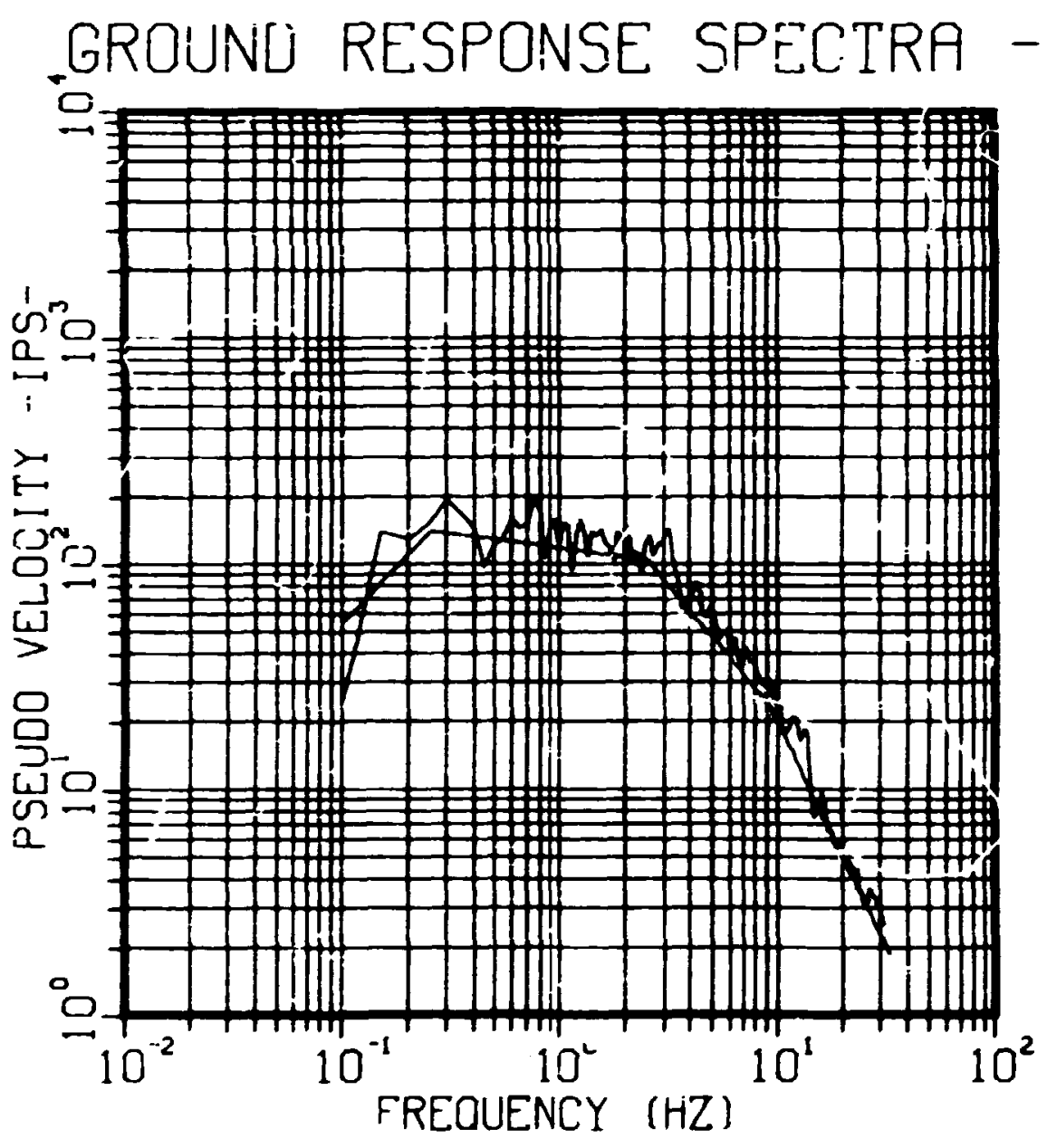

Fig. 13. PSV Response Spectra - GATH.02. 


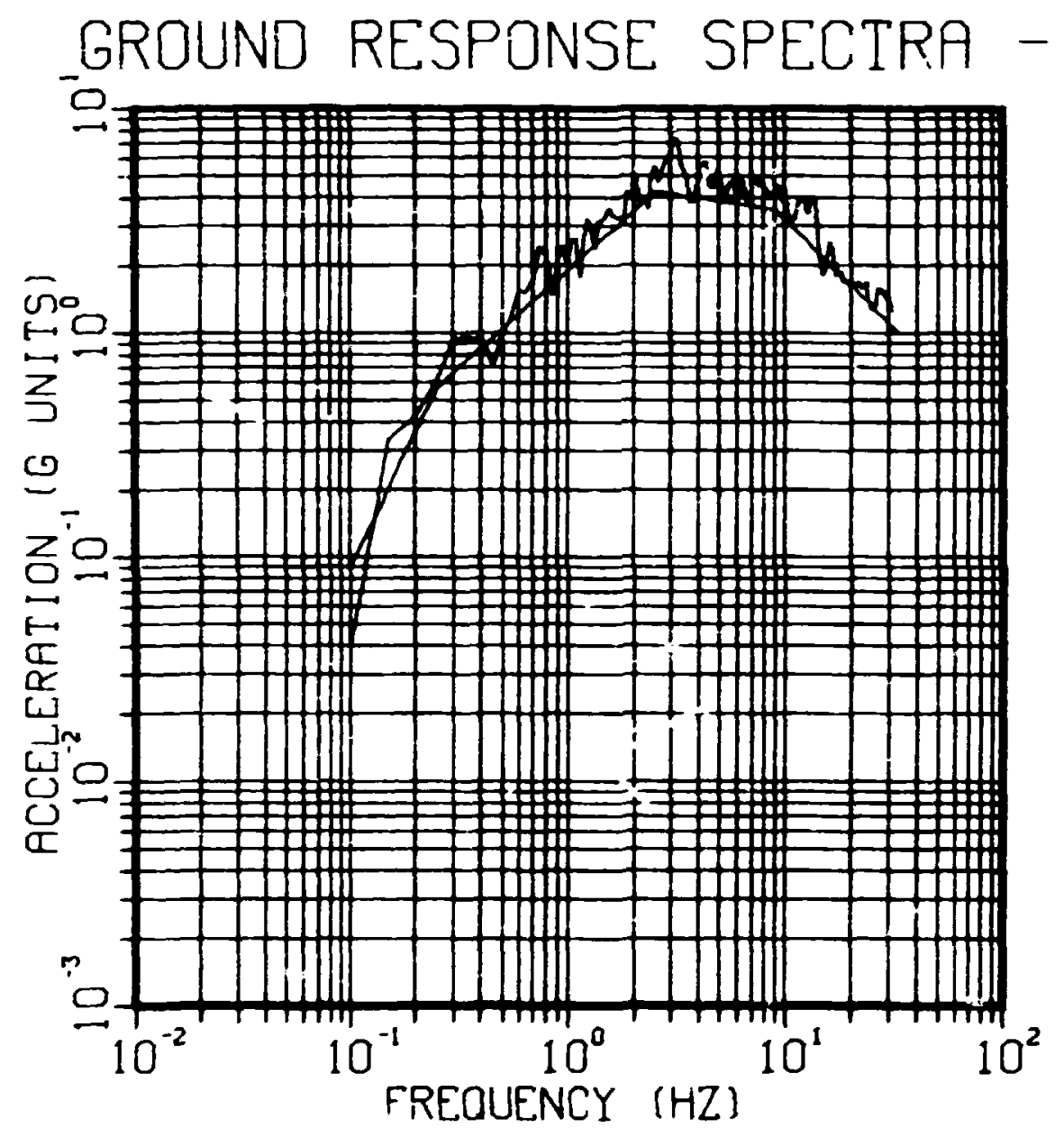

Fig. 14. Acceleration Response Spectra - GATH.02. 


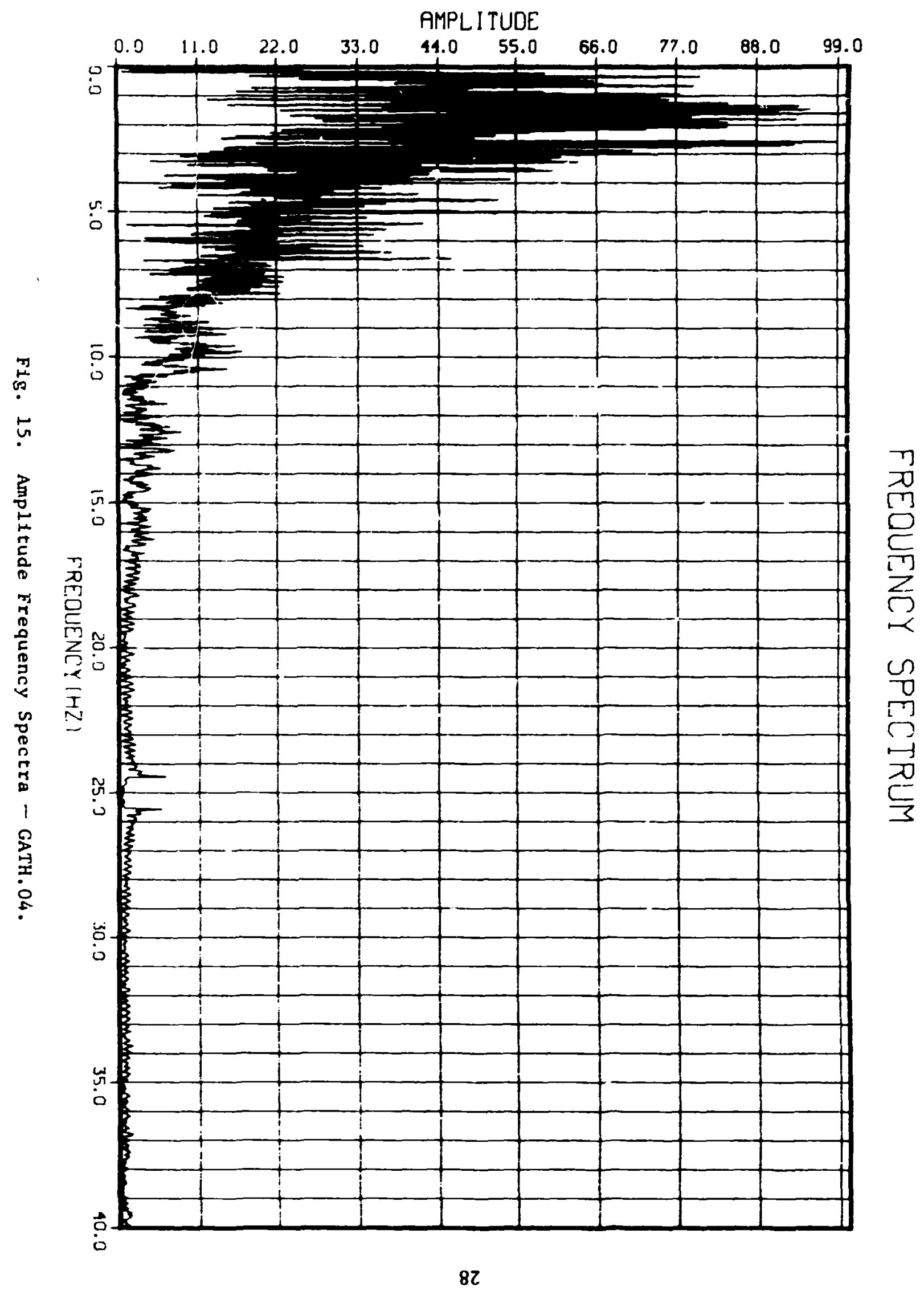




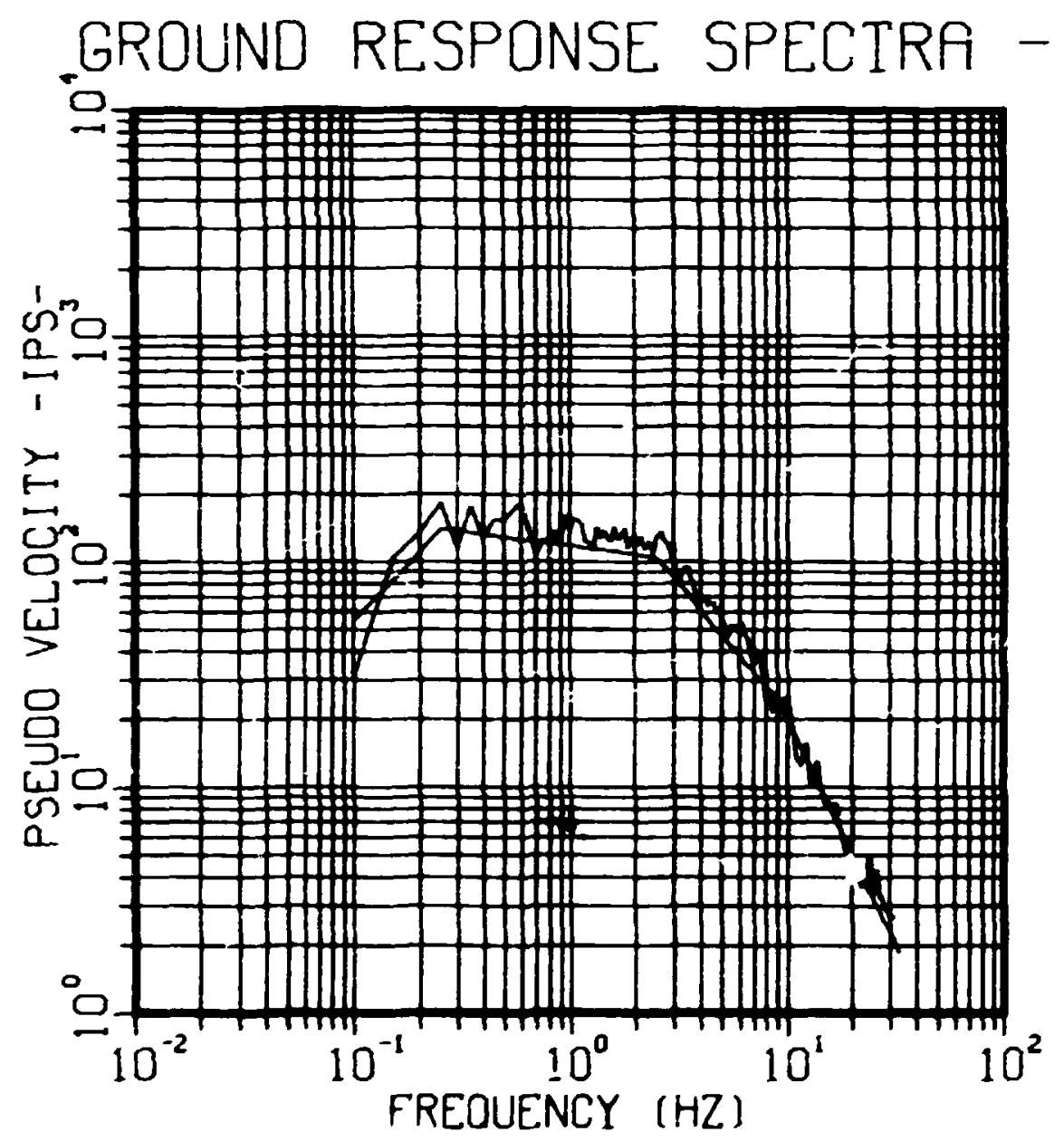

Fig. 16. PSV Response Spectra-GATH.04. 


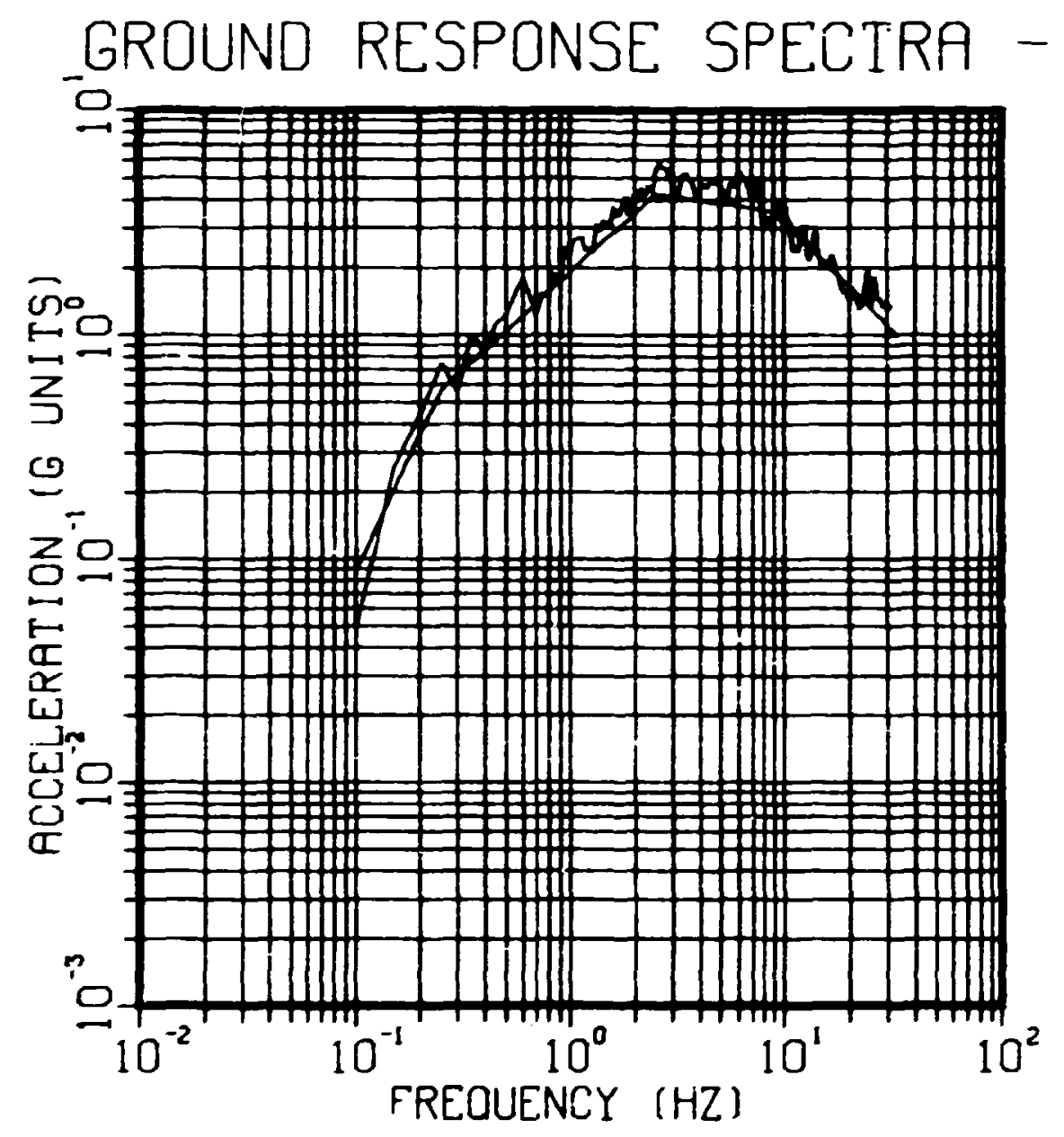

Fig. 17. Acceleration Response Spectra - GATH.04. 
FREQUENCY SPECTRUM

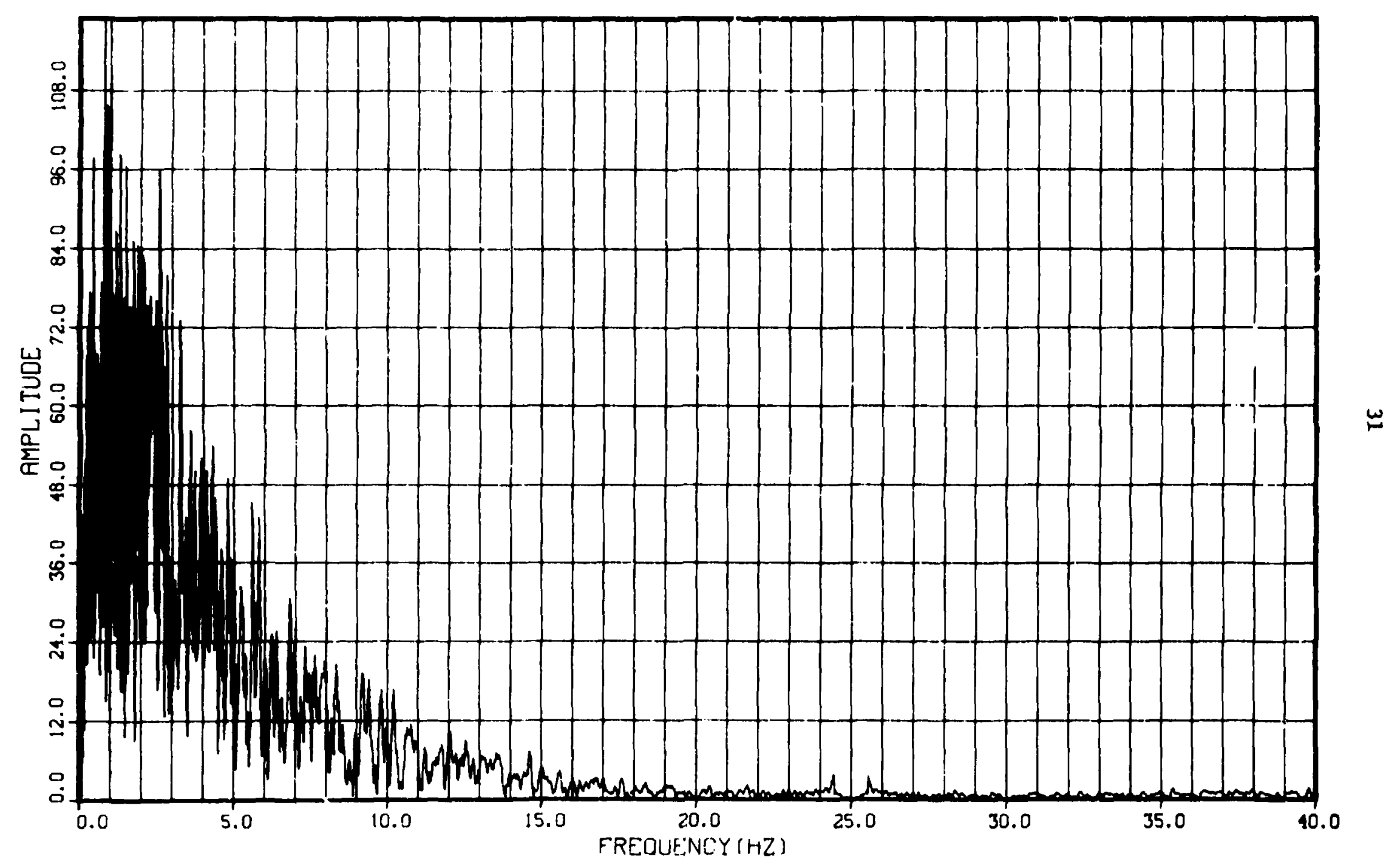

F18. 18. Amplitude Frequency Spectra - GATH. 09. 


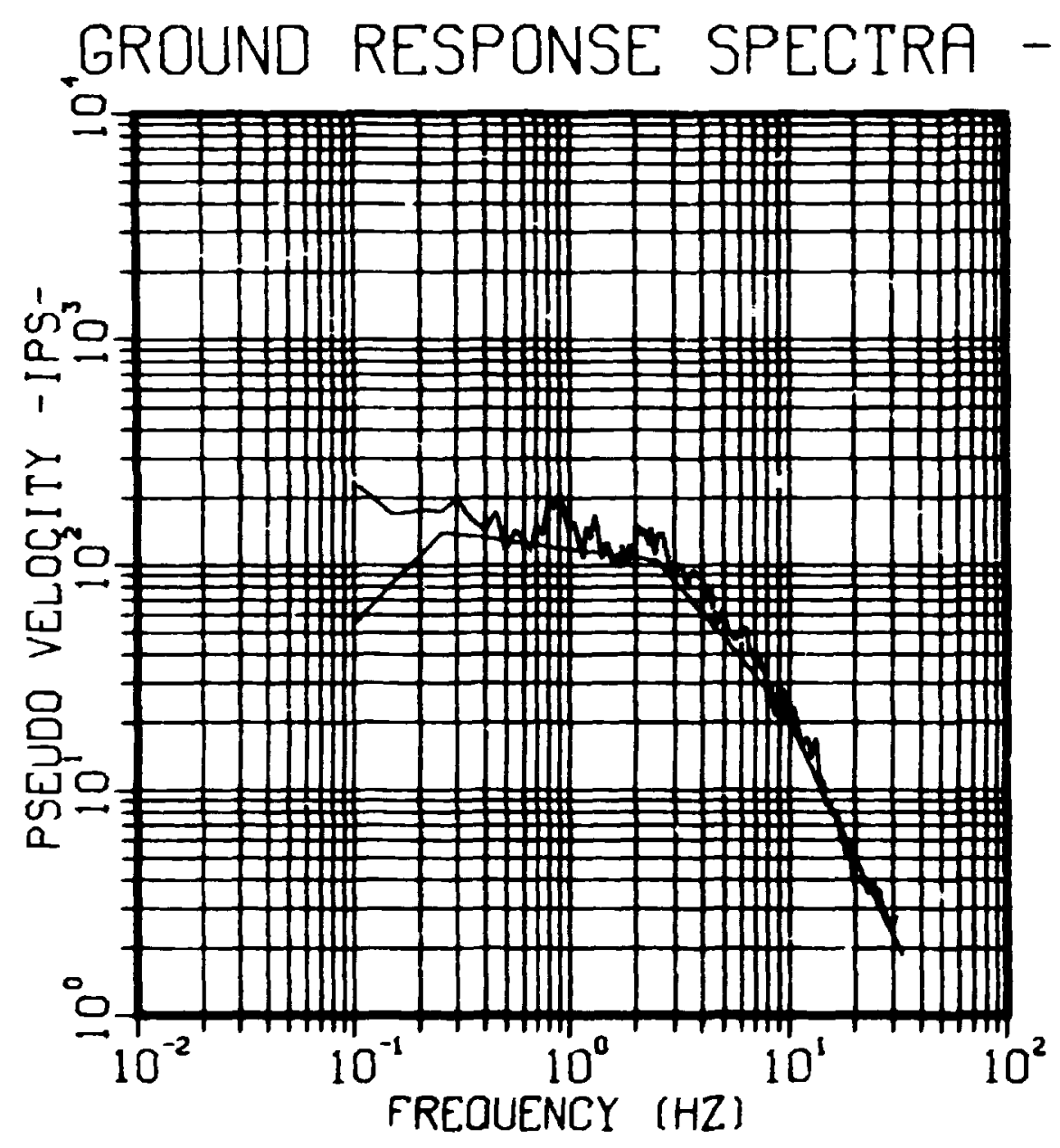

F18. 19. PSV Regponse Spectra - GATH.09. 


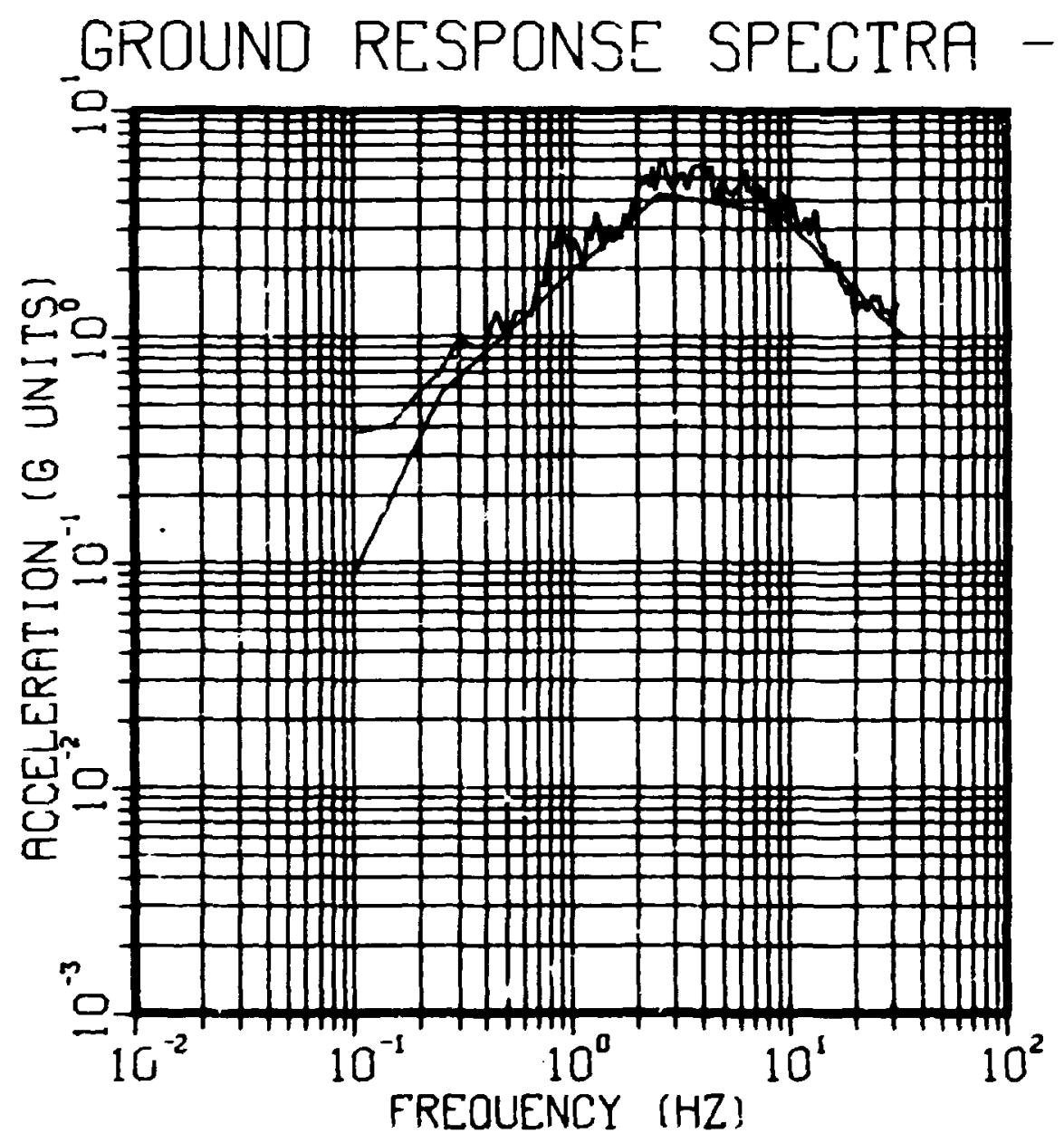

Fig. 20. Acceleration Response Spectra - GATH.09. 


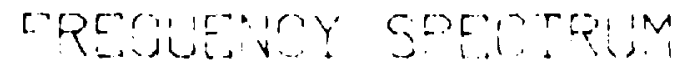

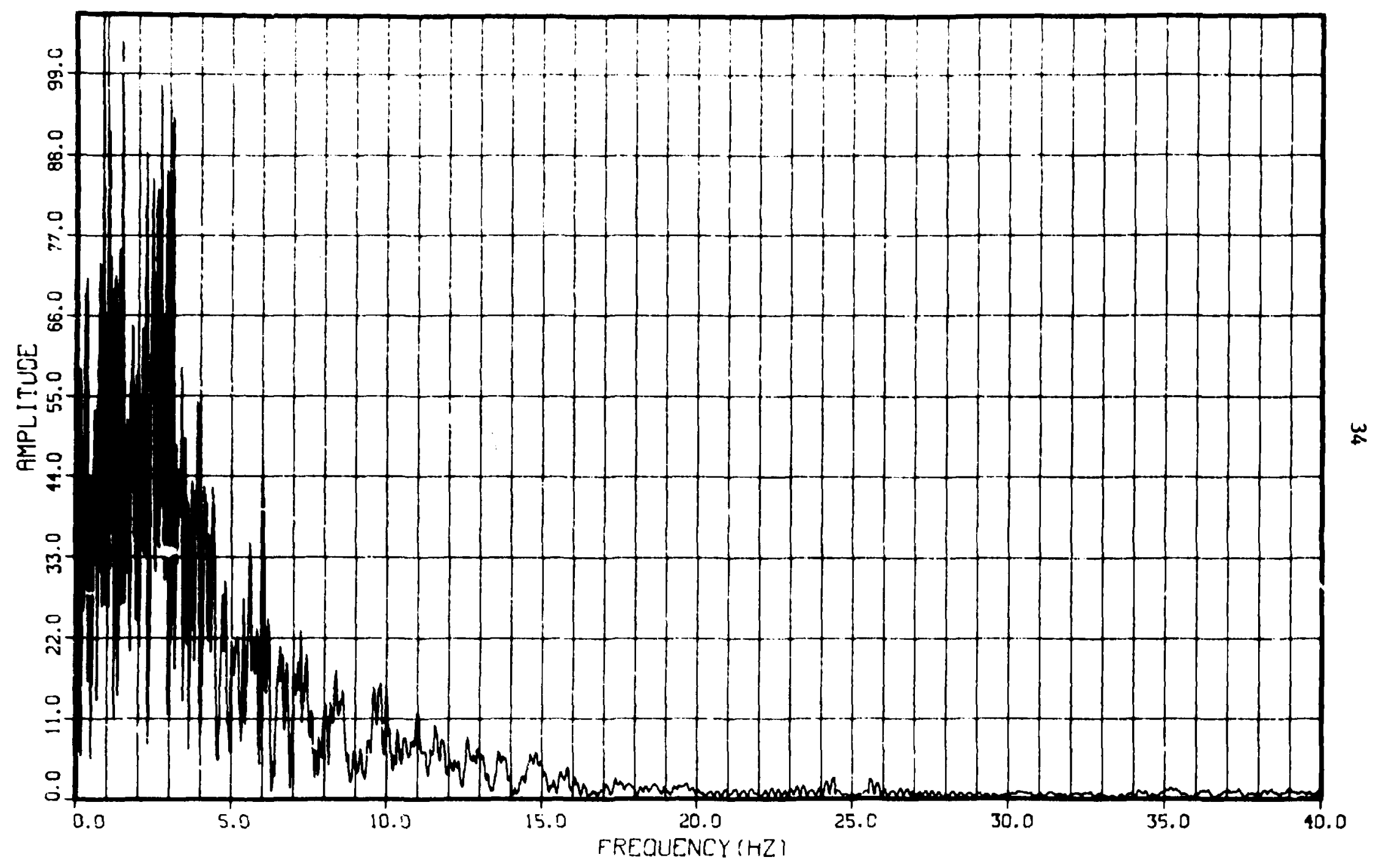

F1g. 21. Ampl1L.fe Frequency Spectra - GATH.10. 


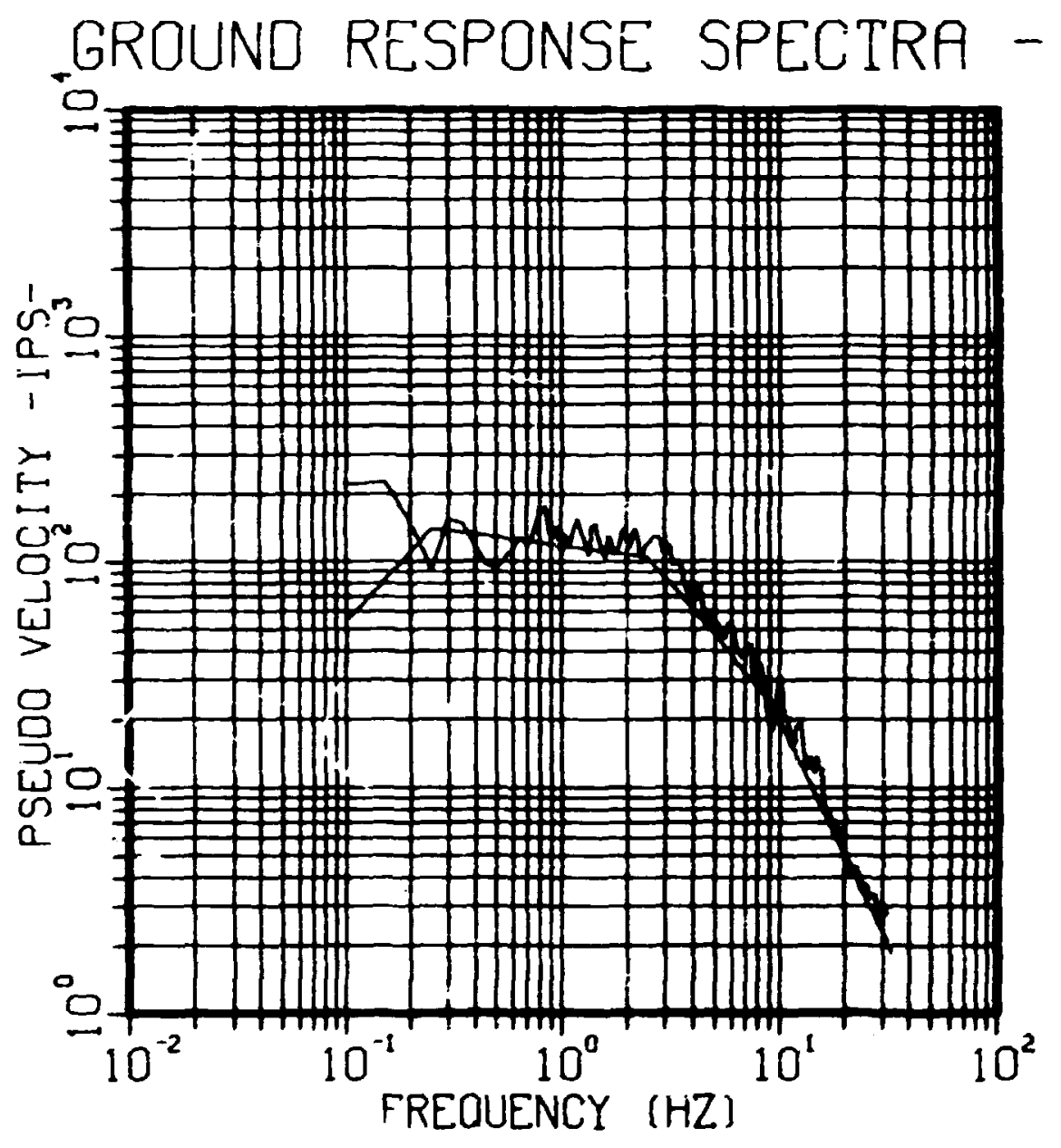

F1g. 22. PSV Response Spectra - GATH.10. 


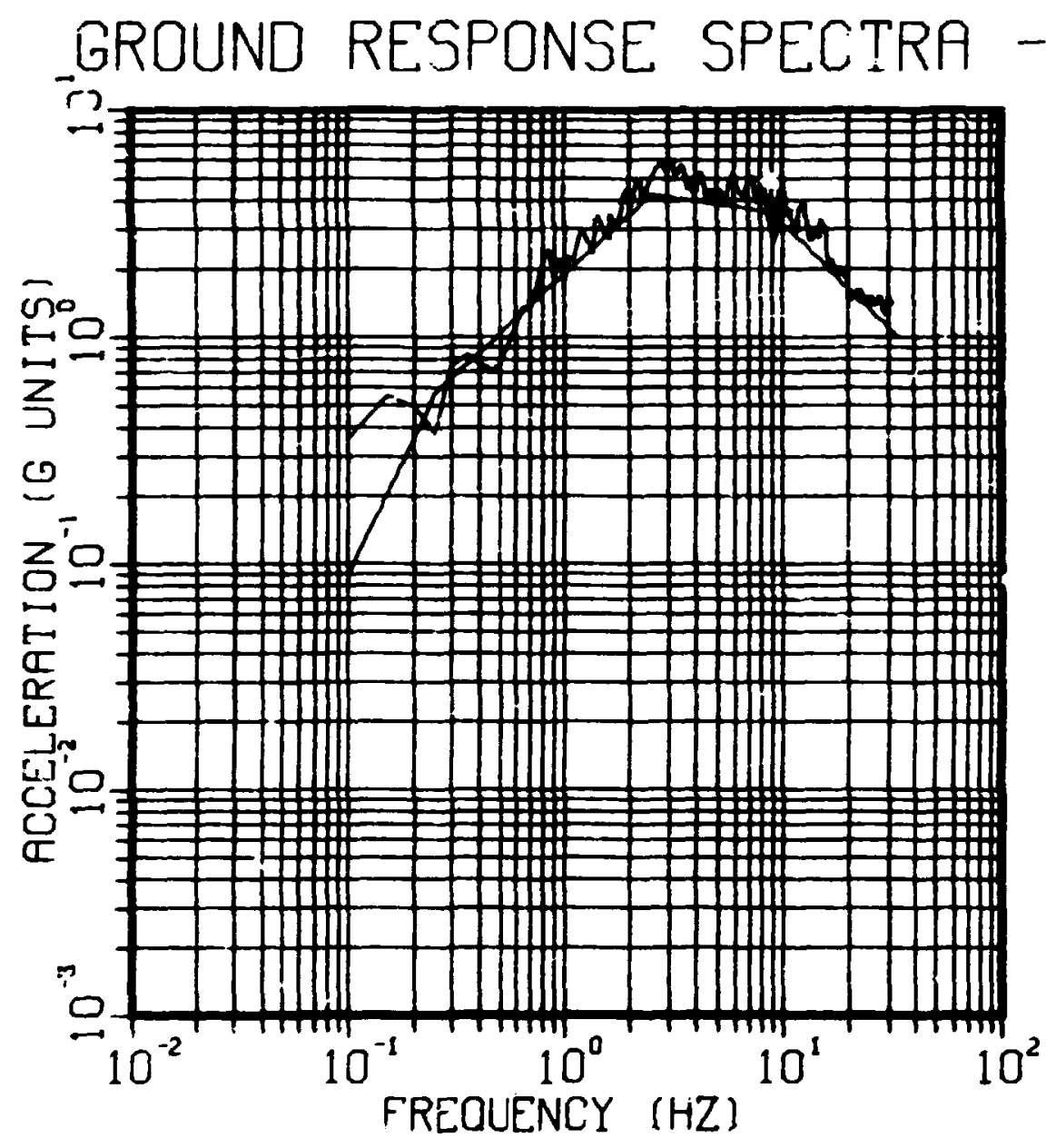

Fig. 23. Acceleration Response Spectra - GATH.10. 


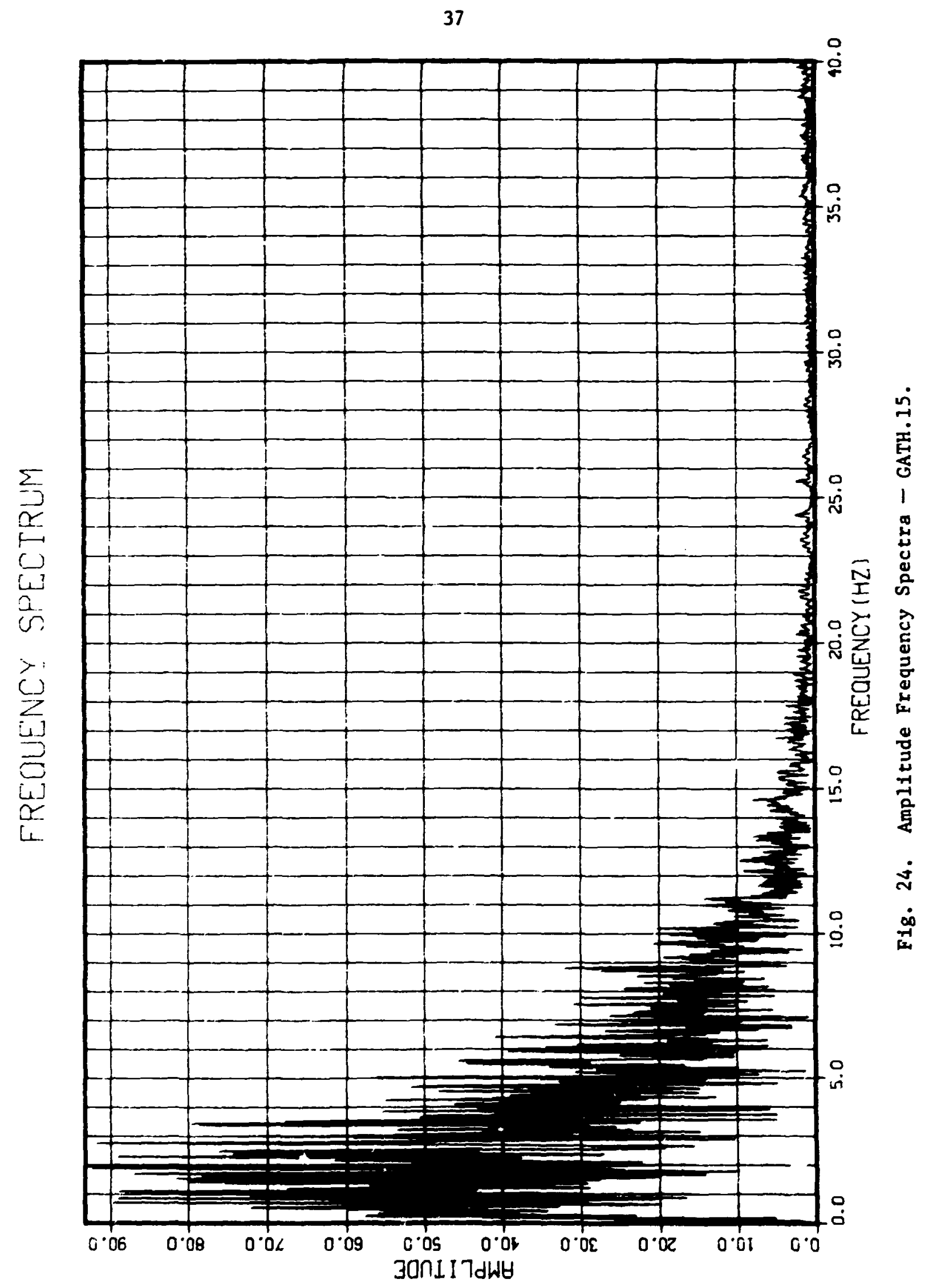




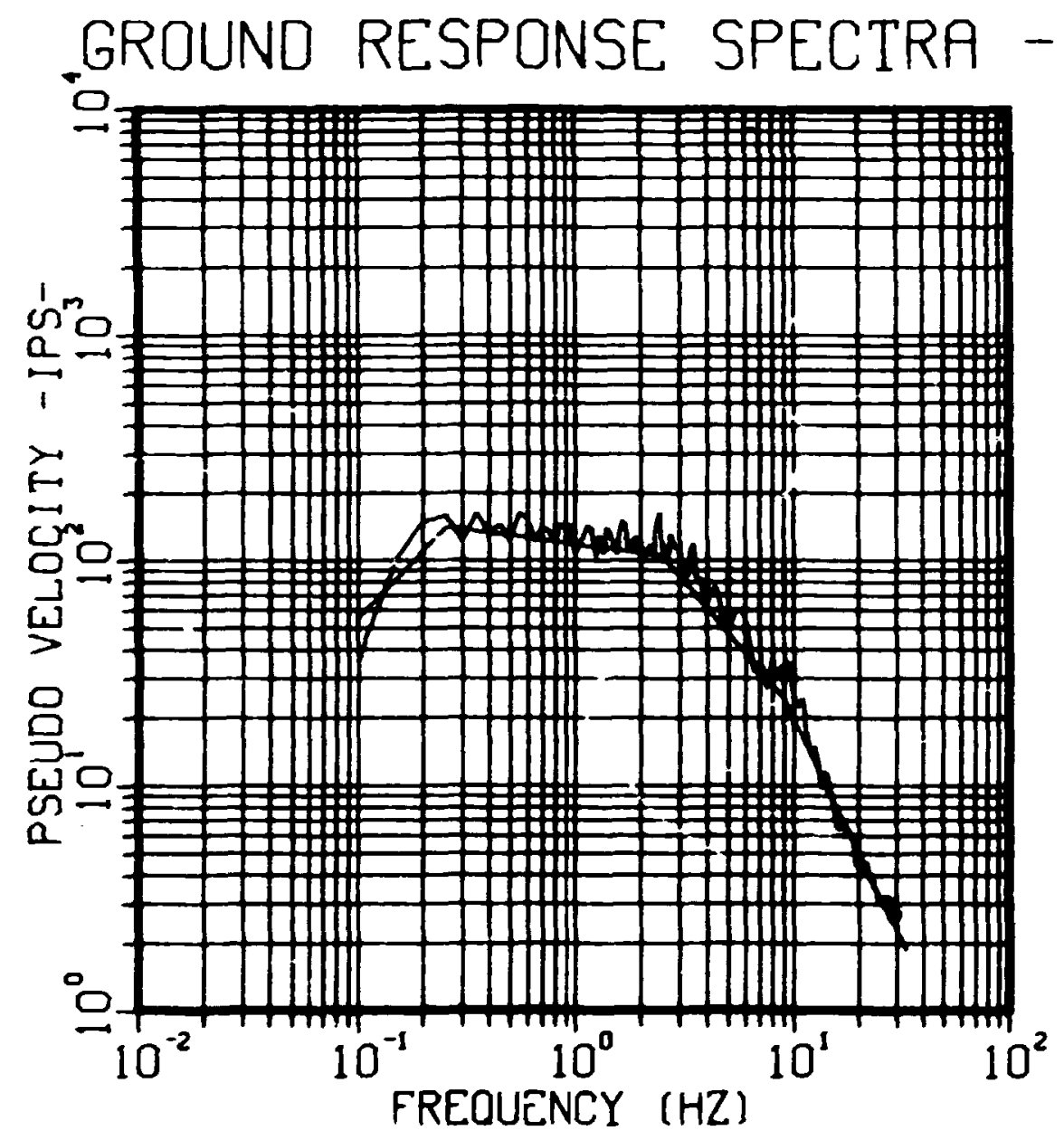

Fig. 25. PSV Response Spectra-GATH.15. 


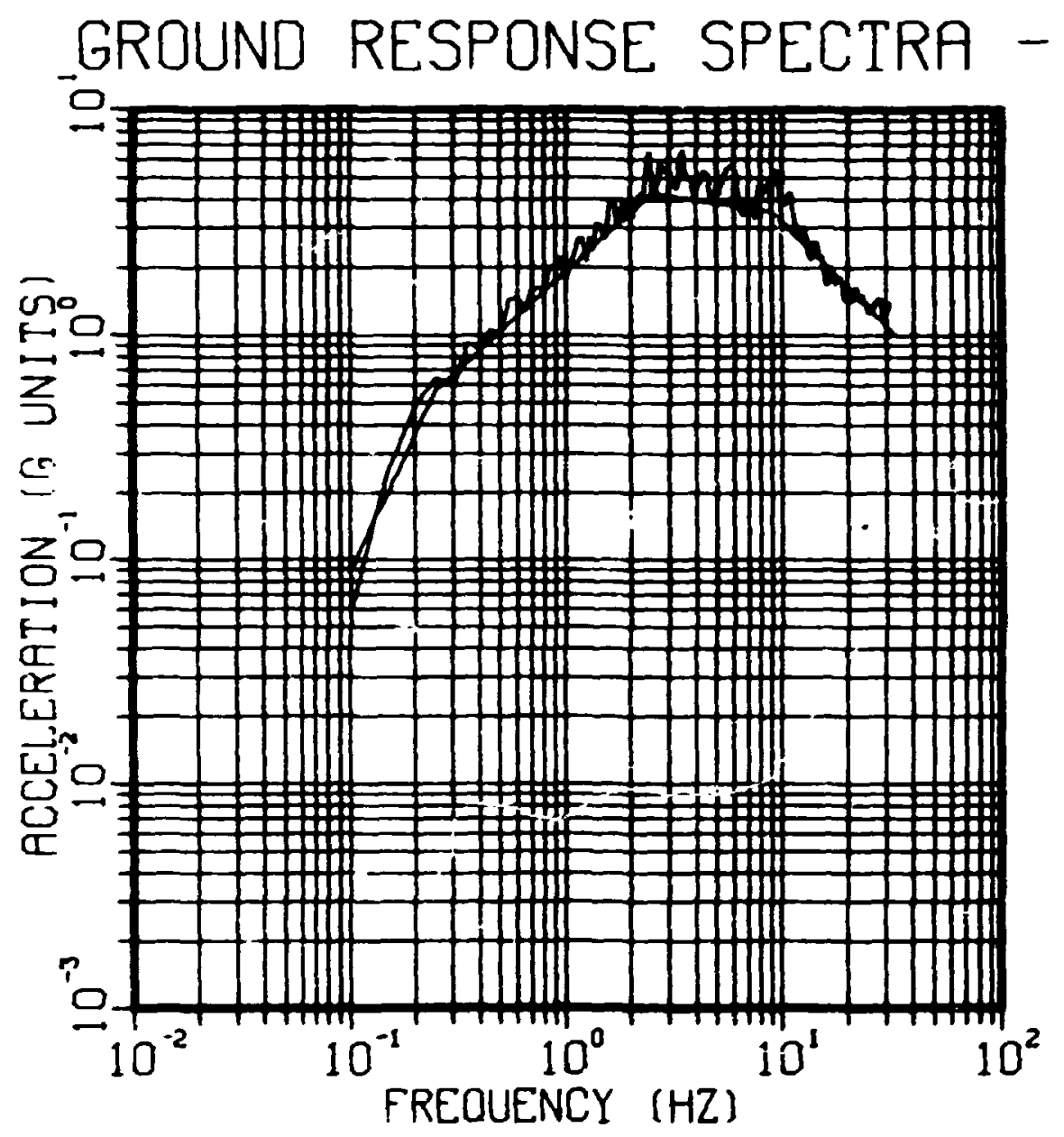

Fig. 26. Acceleration Response Spectra - GATH.15. 


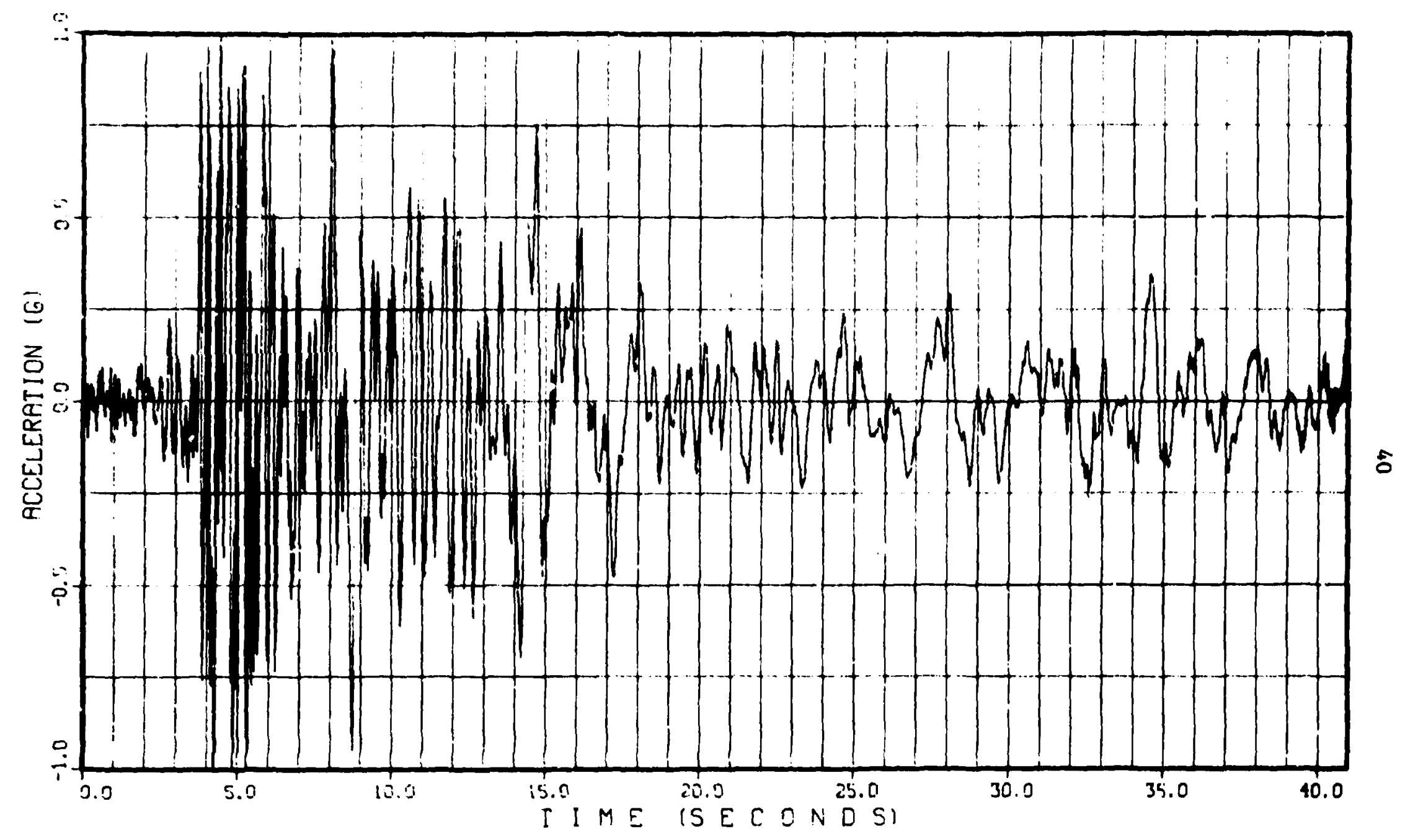

FIg. 27. GATH.02 - Acceleration. 


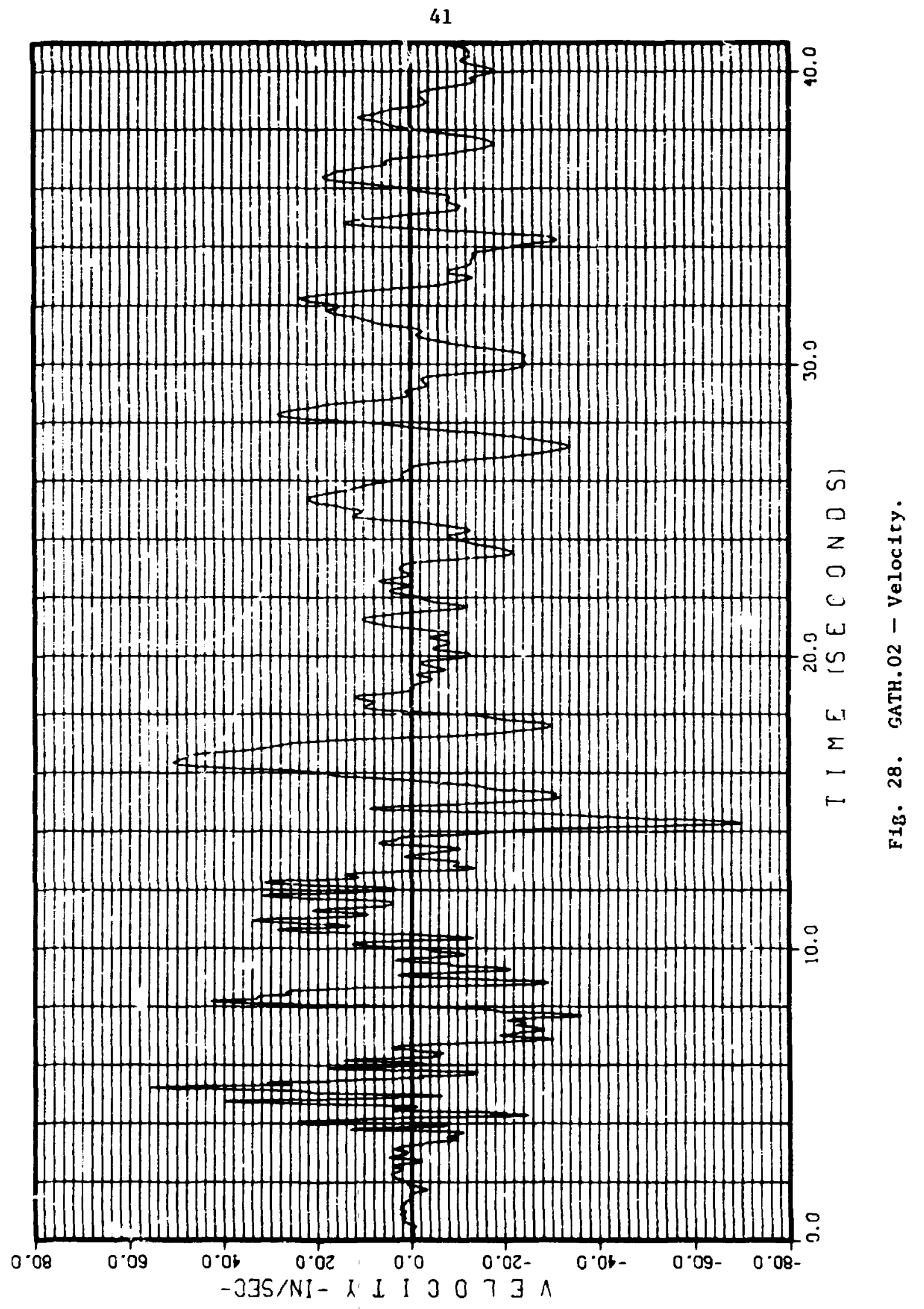




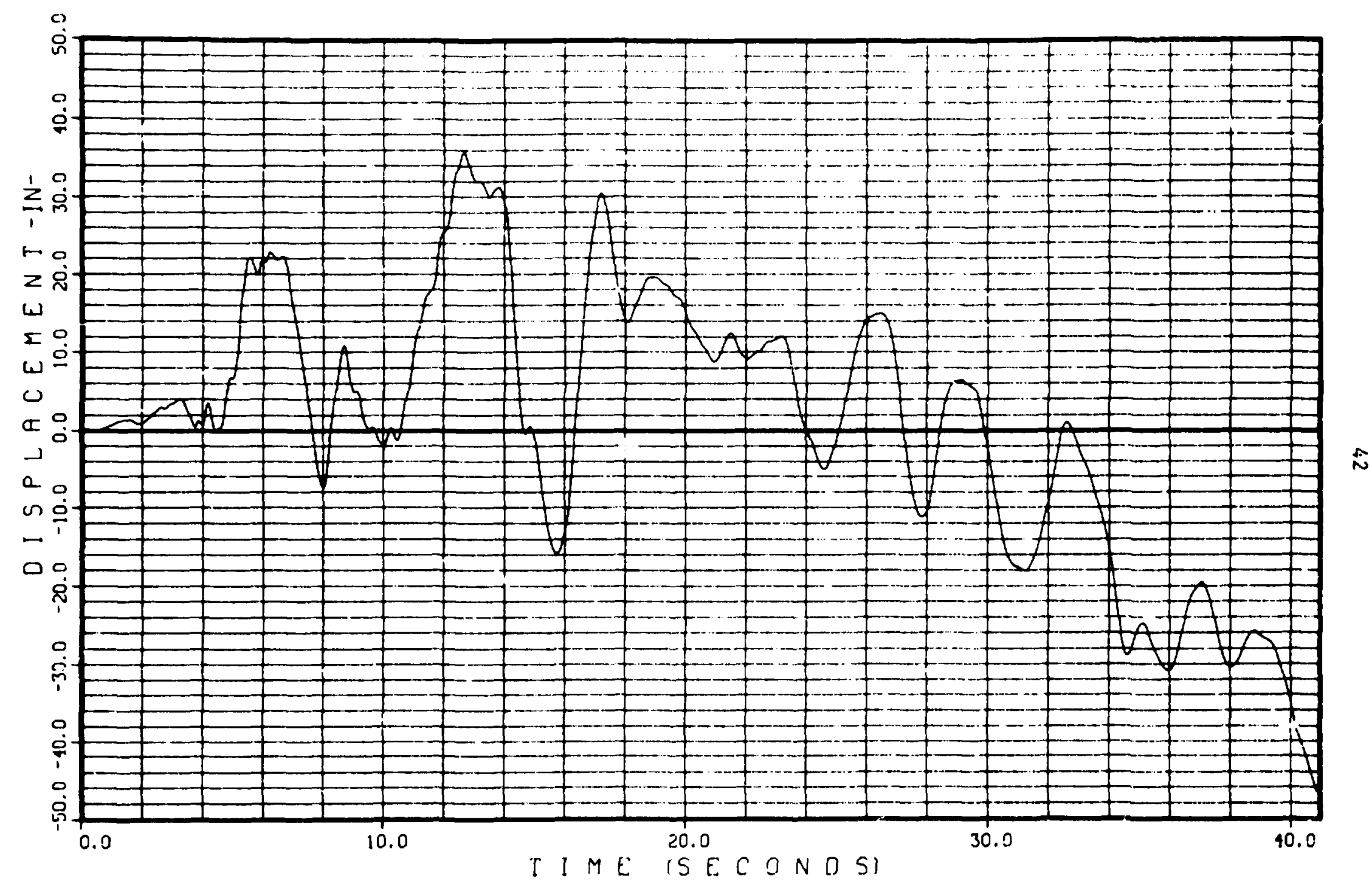

F1g. 29. GATH.02 - Displacement. 


$$
f+\infty
$$


44

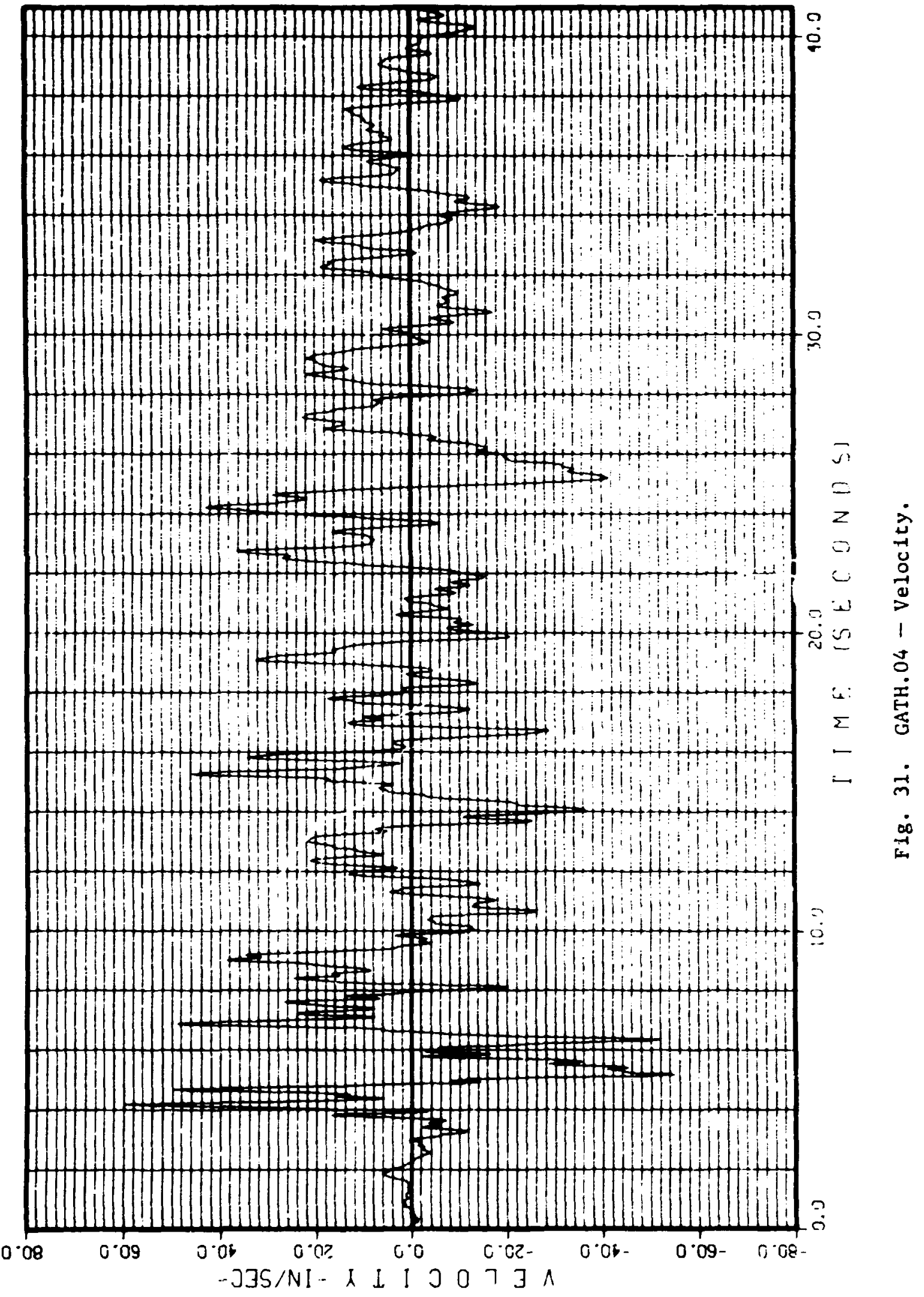




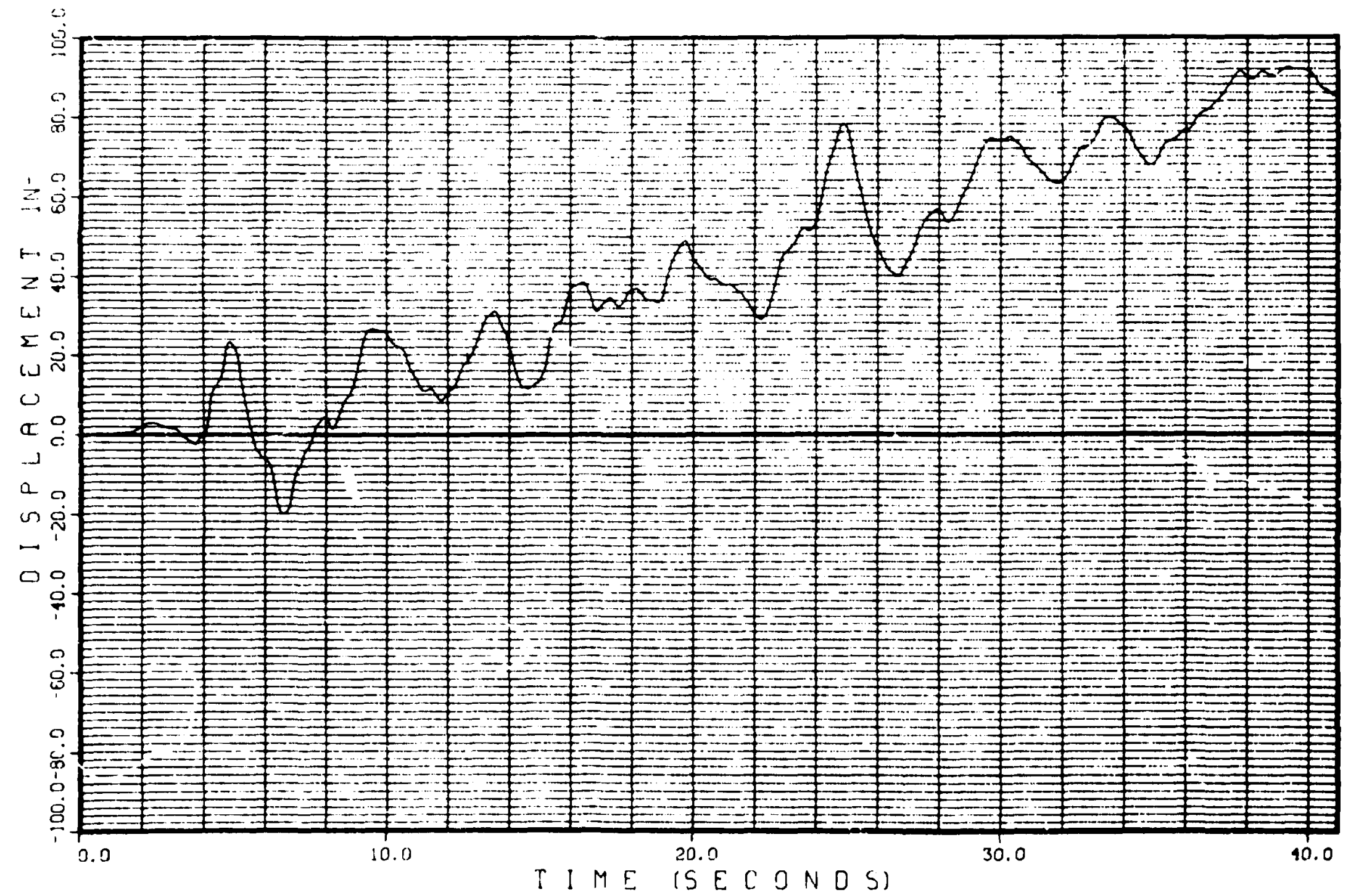

Fig. 32. GATH.04 - Displacement. 


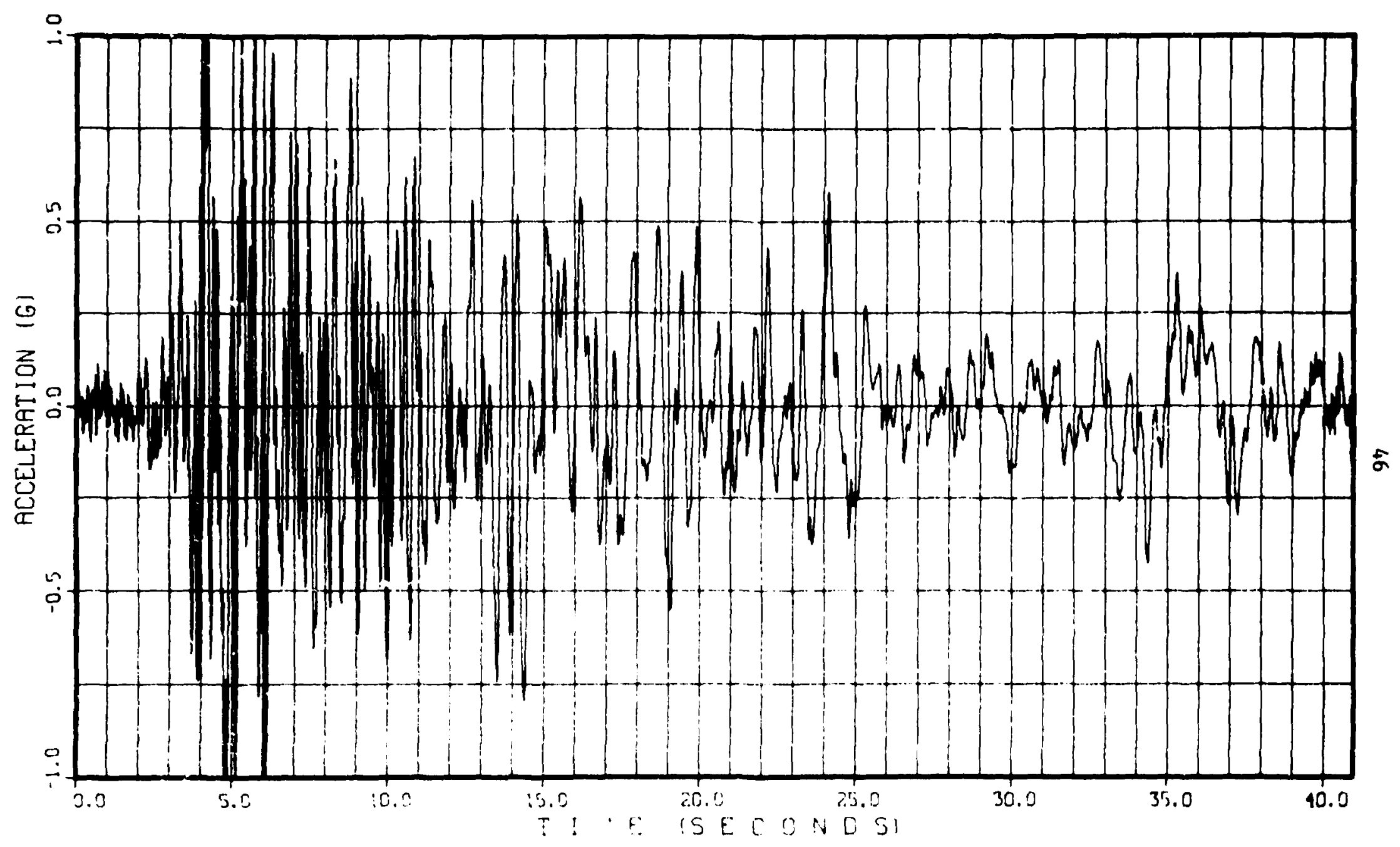

F1g. 33. GATH.09 - Velocity. 


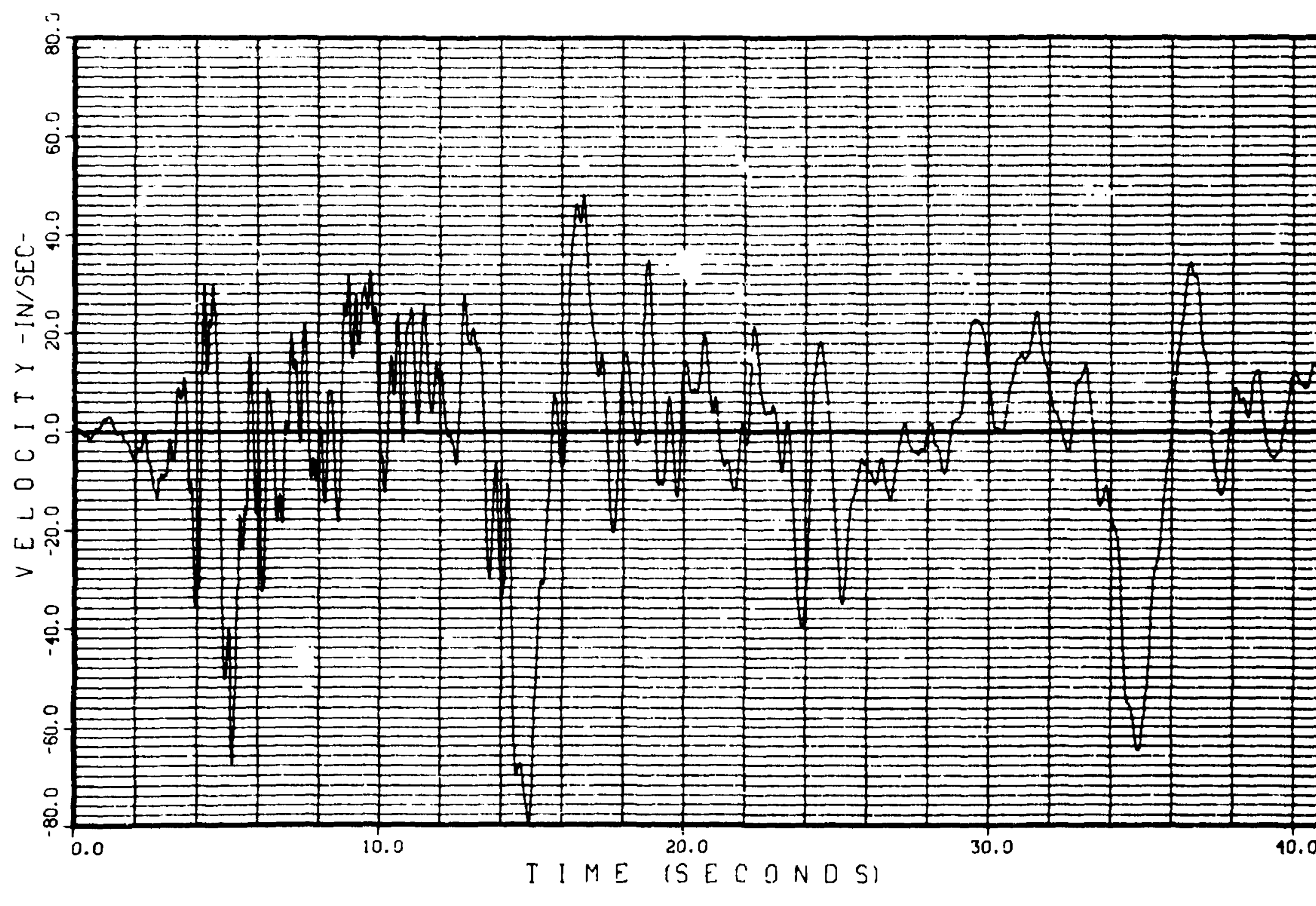

Fig. 34. GATH.09 - Velocity. 


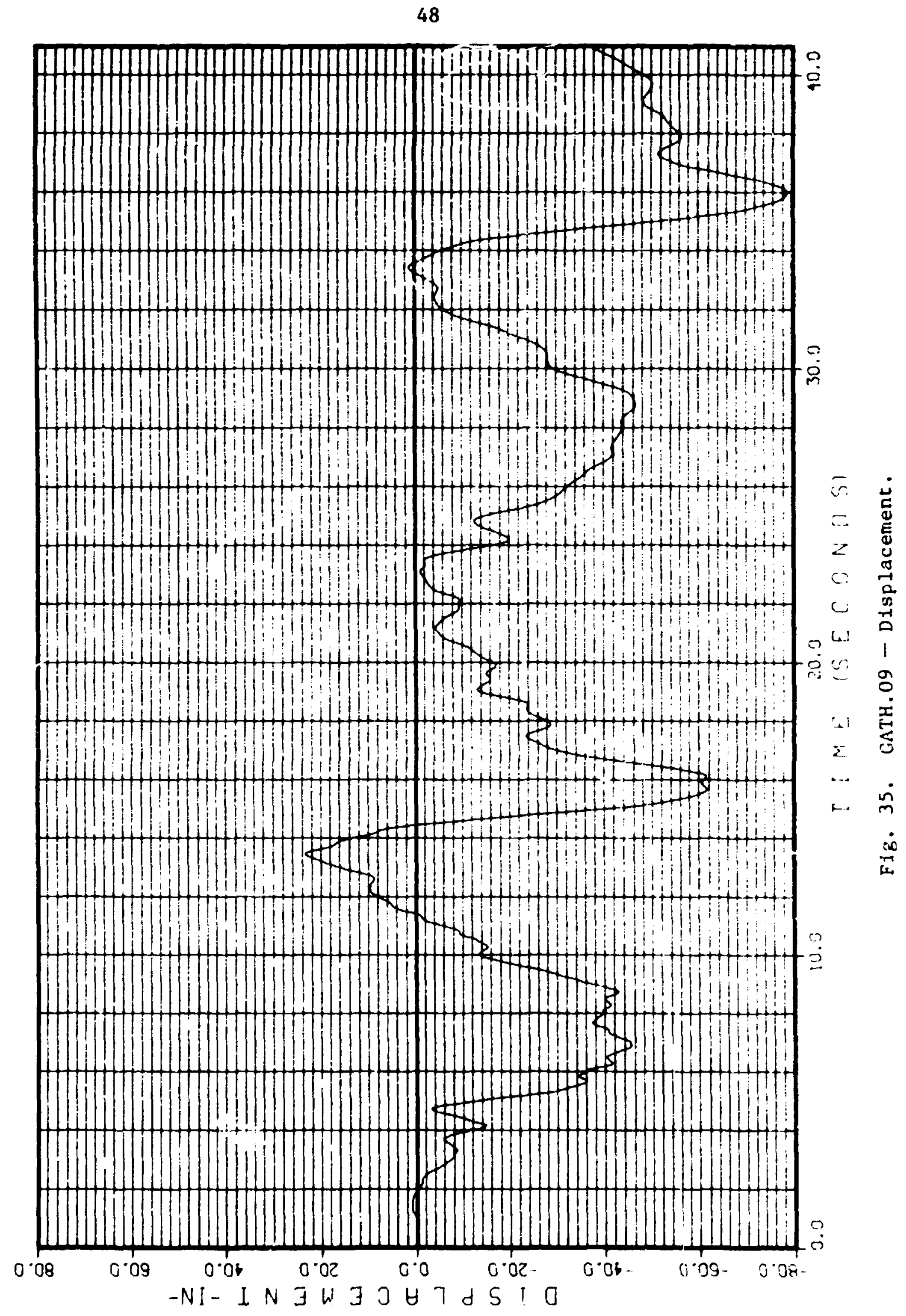




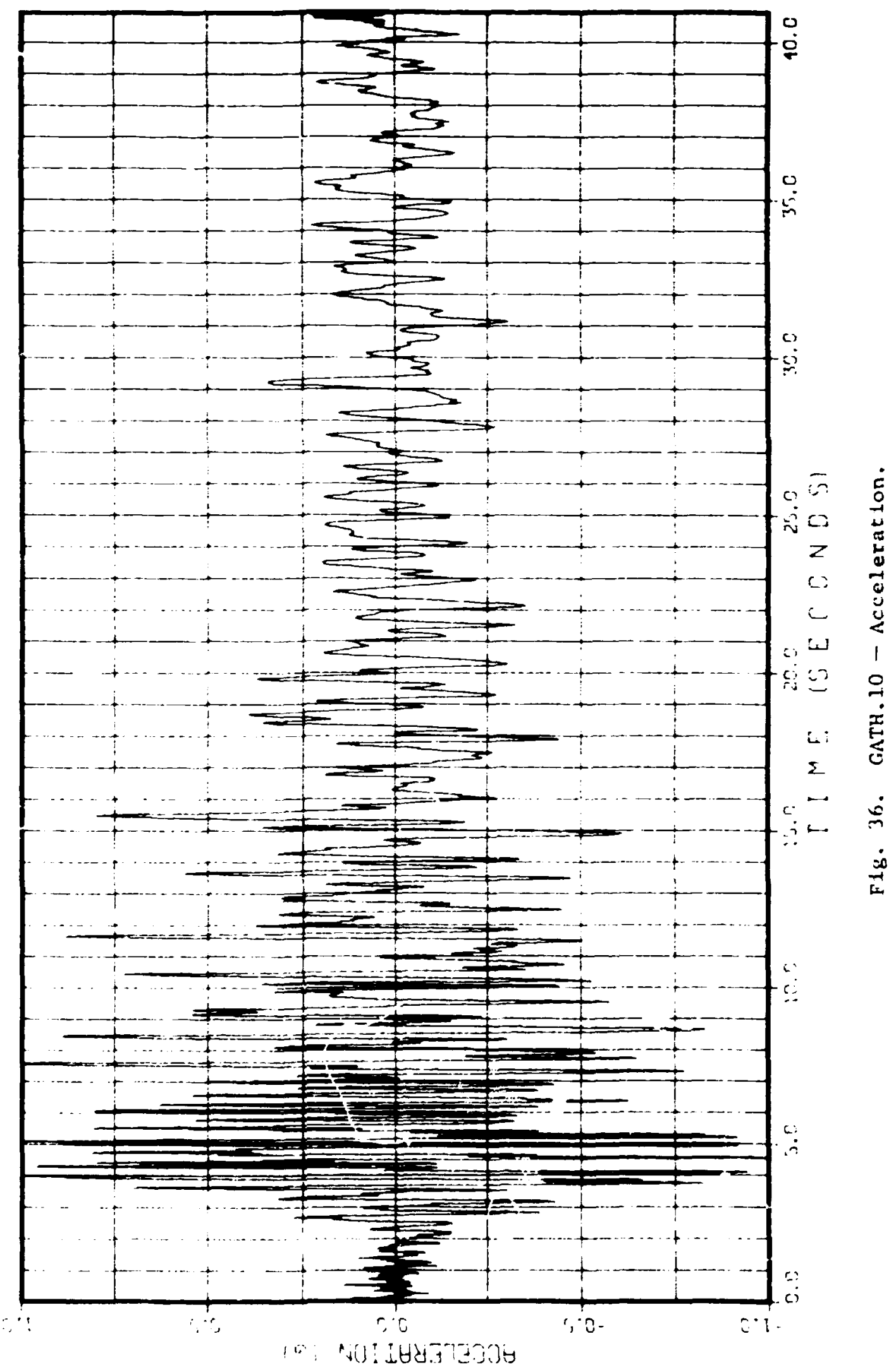




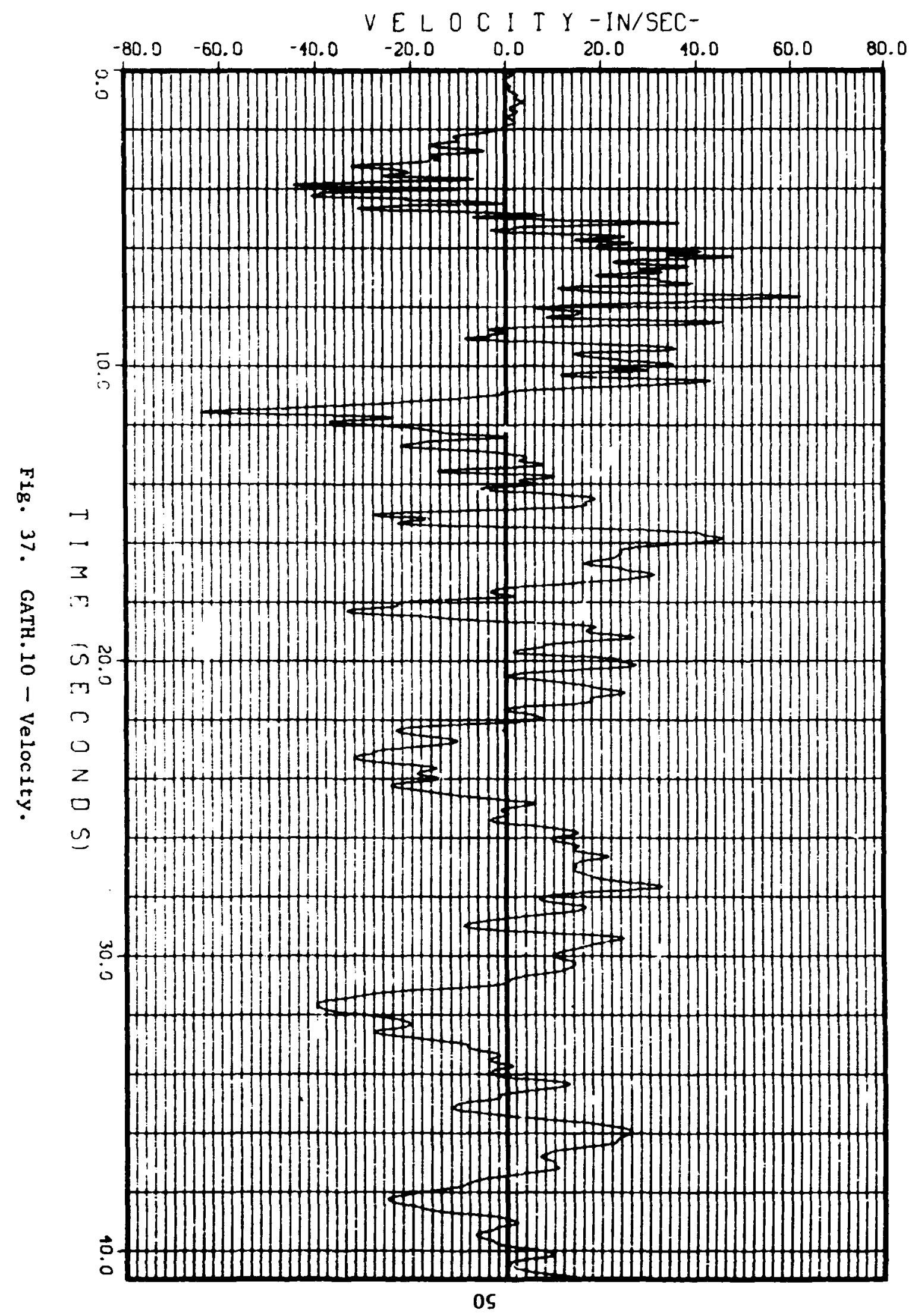




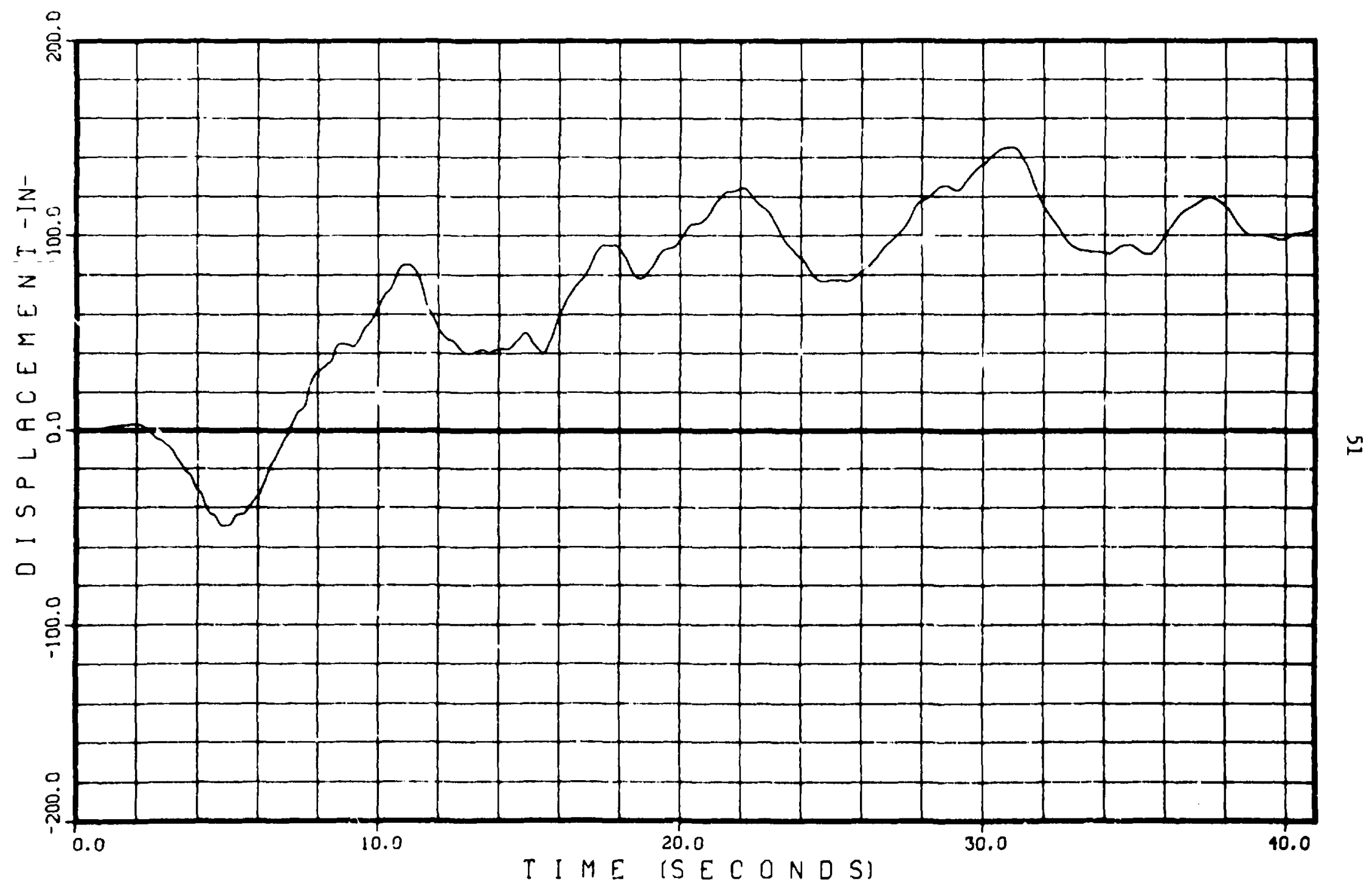

Fig. 38. GATH.10-Displacement. 


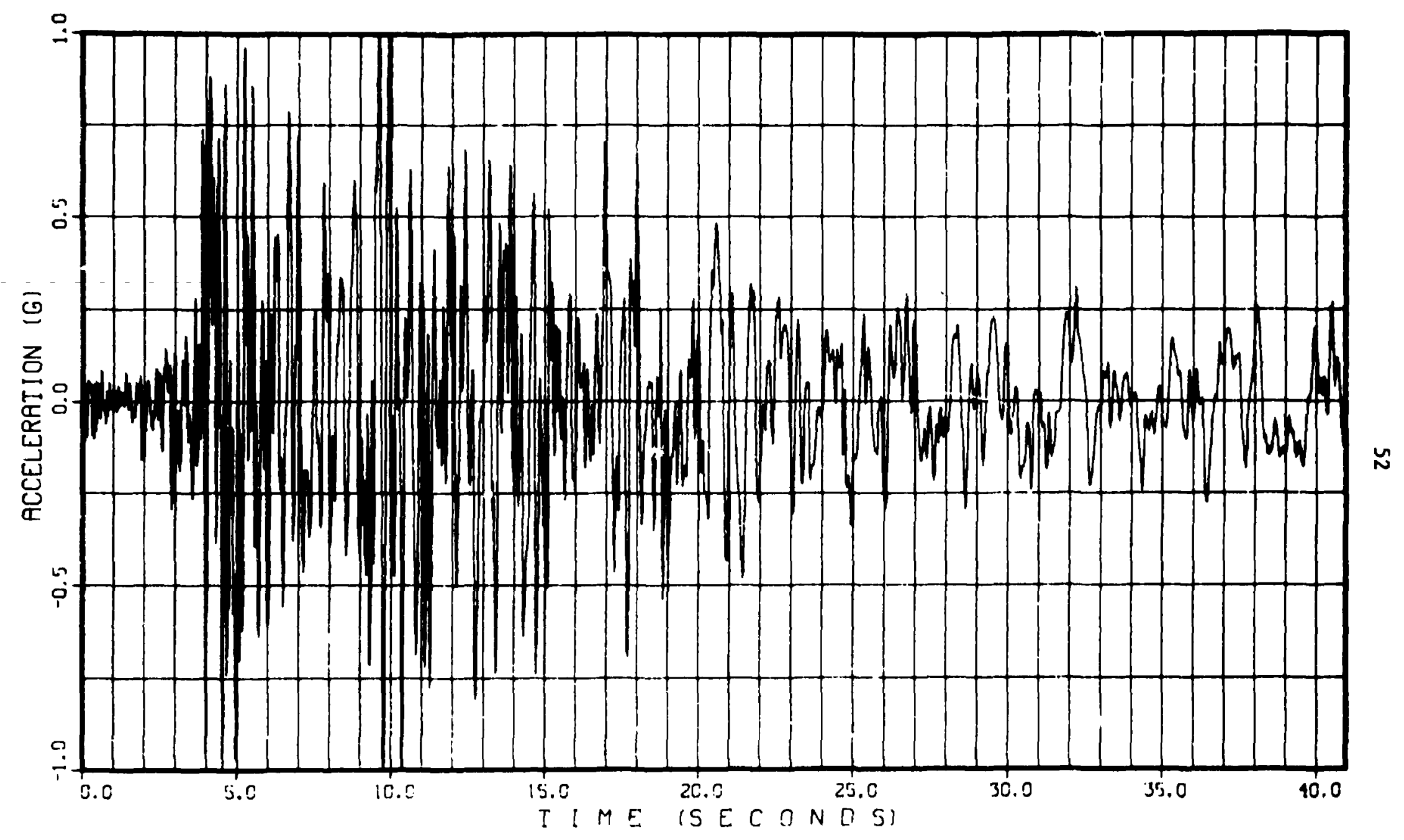

F1g. 39. GATH.15 - Acceleration. 


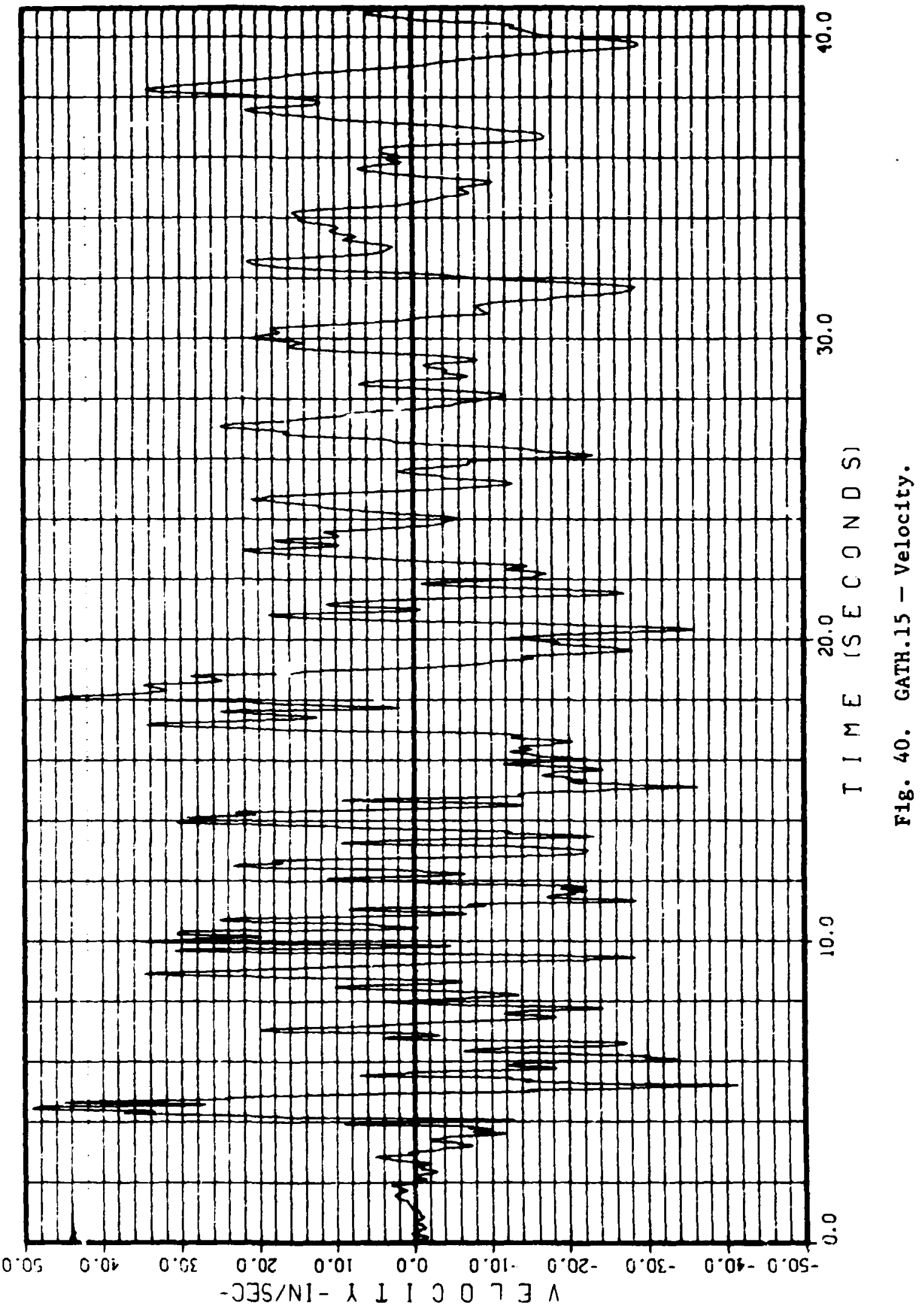




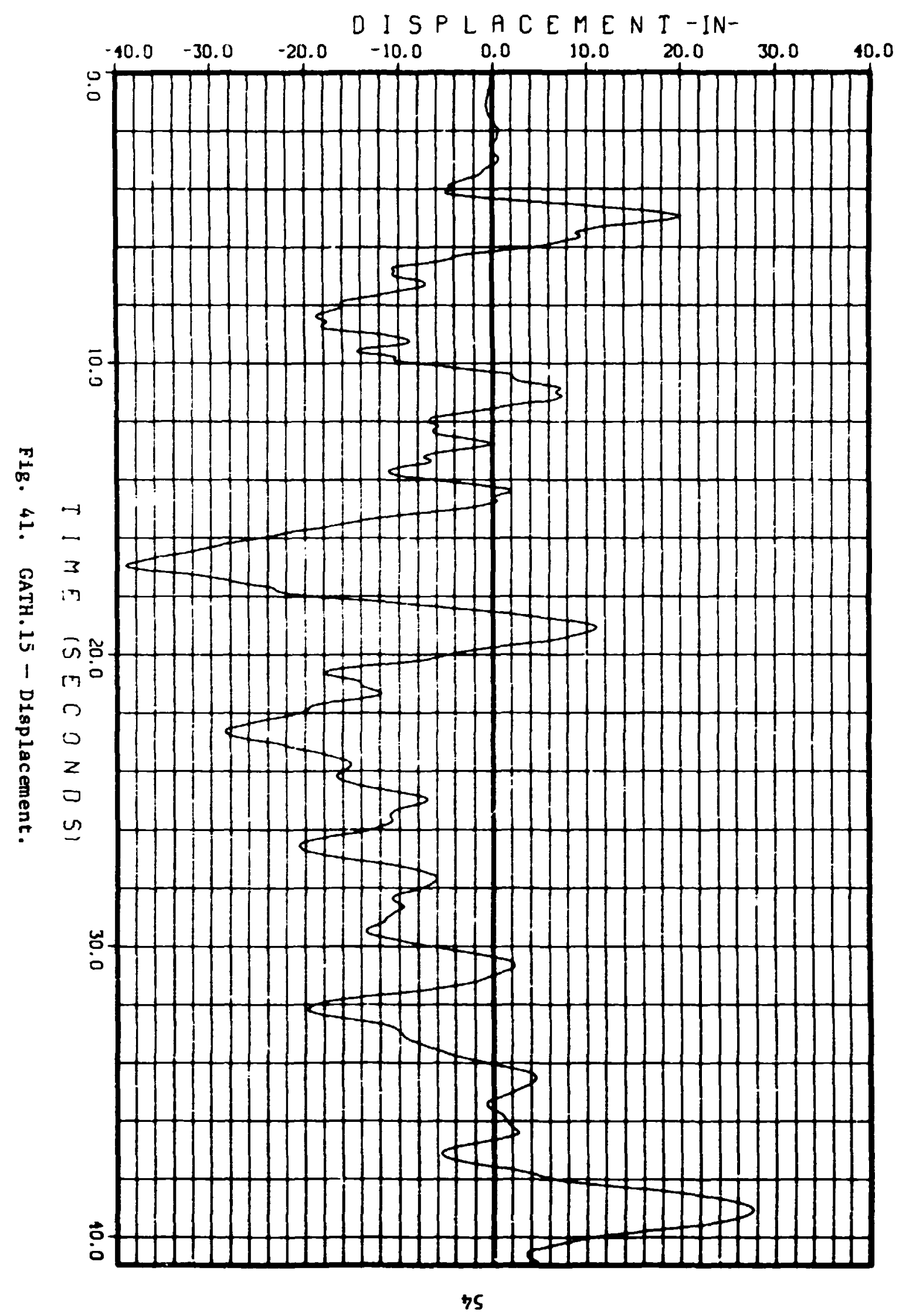




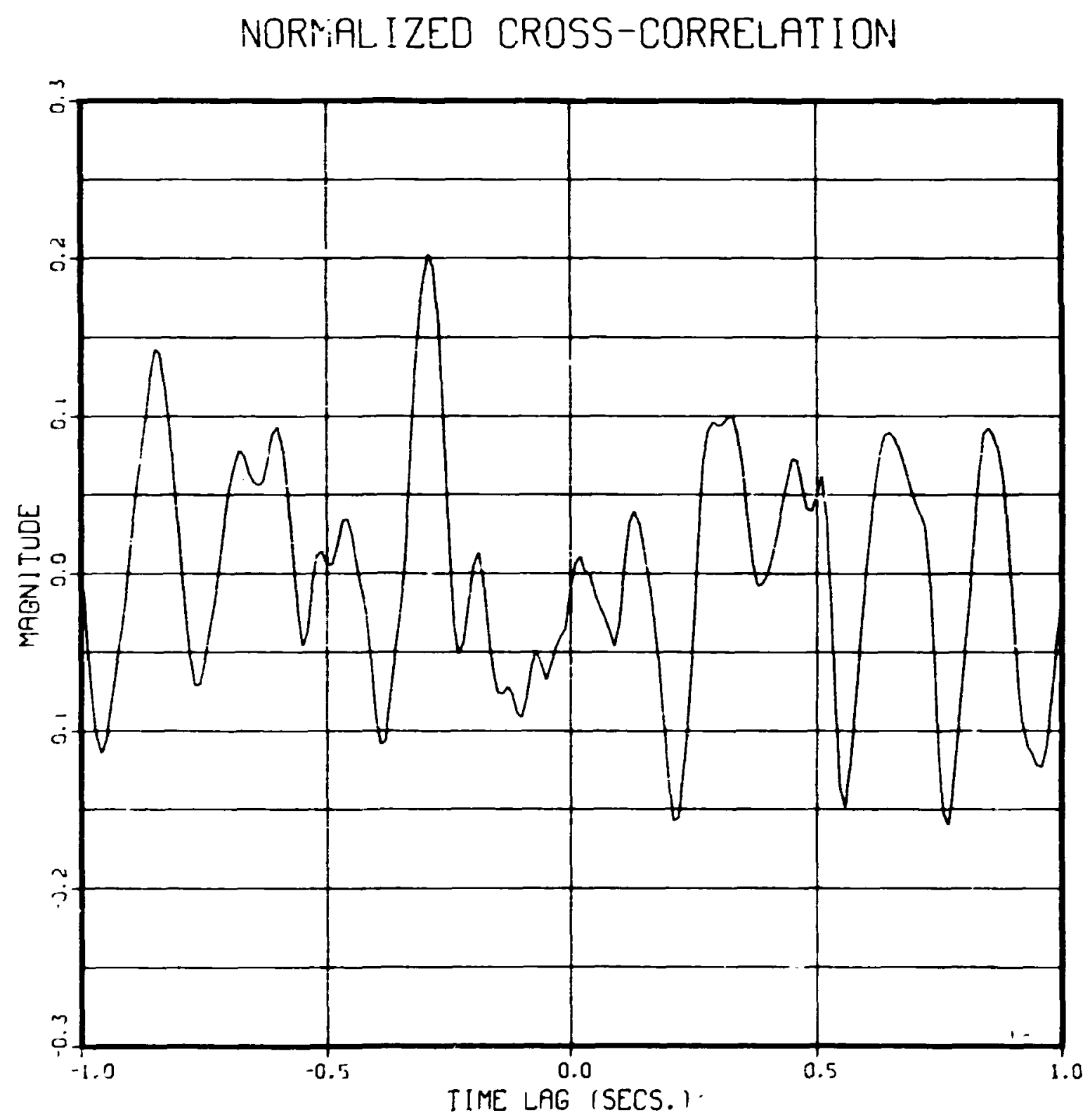

Fig. 42. Normalized Cross-Correlation, GATH.02 - GATH.04. 
NORMALIZED CROSS-CORRELAT ION

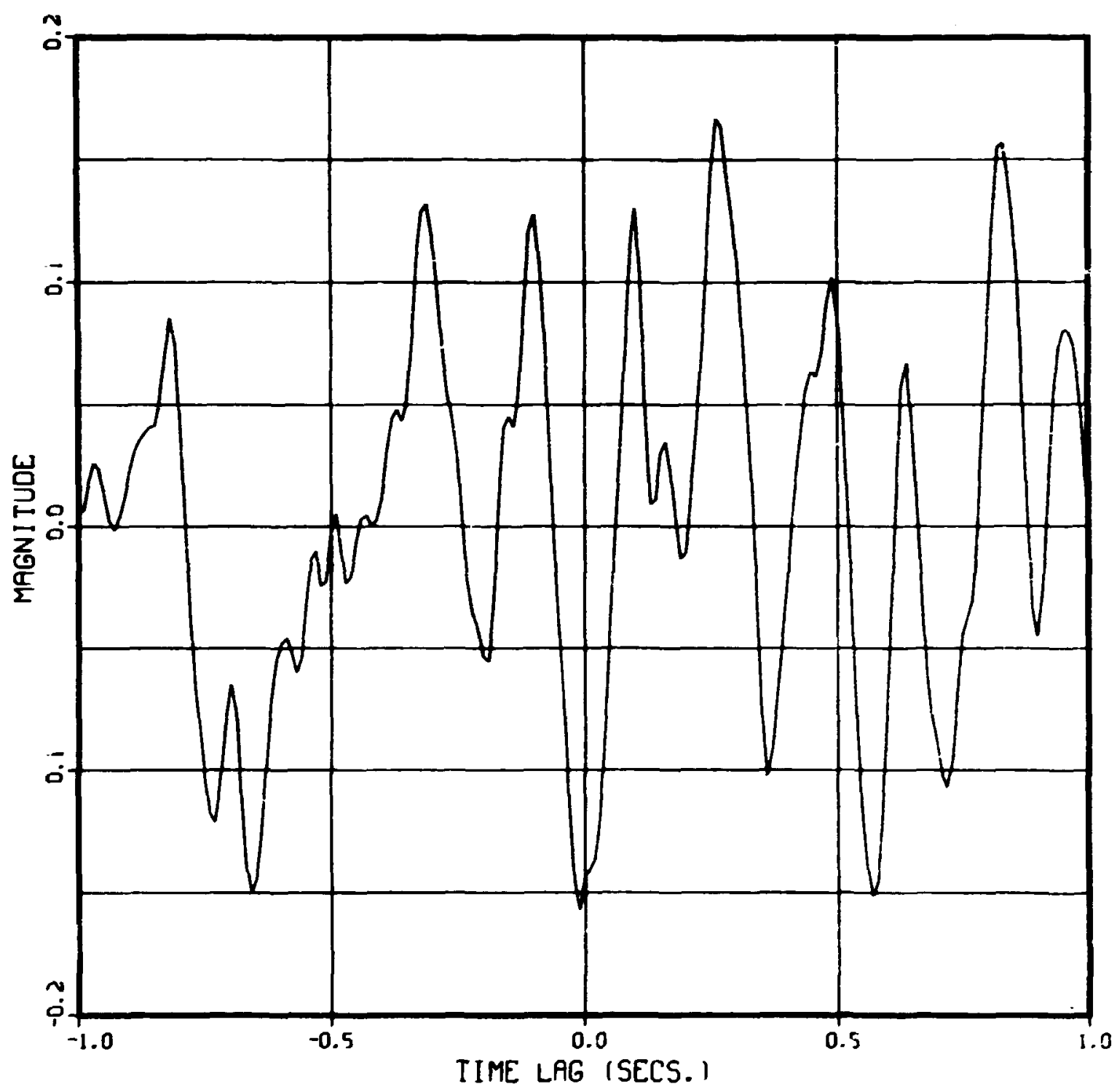

Fig. 43. Normalized Cross-Correlation, GATH.02 - GATH.09. 
NORMAL I ZED CROSS-CORRELATION

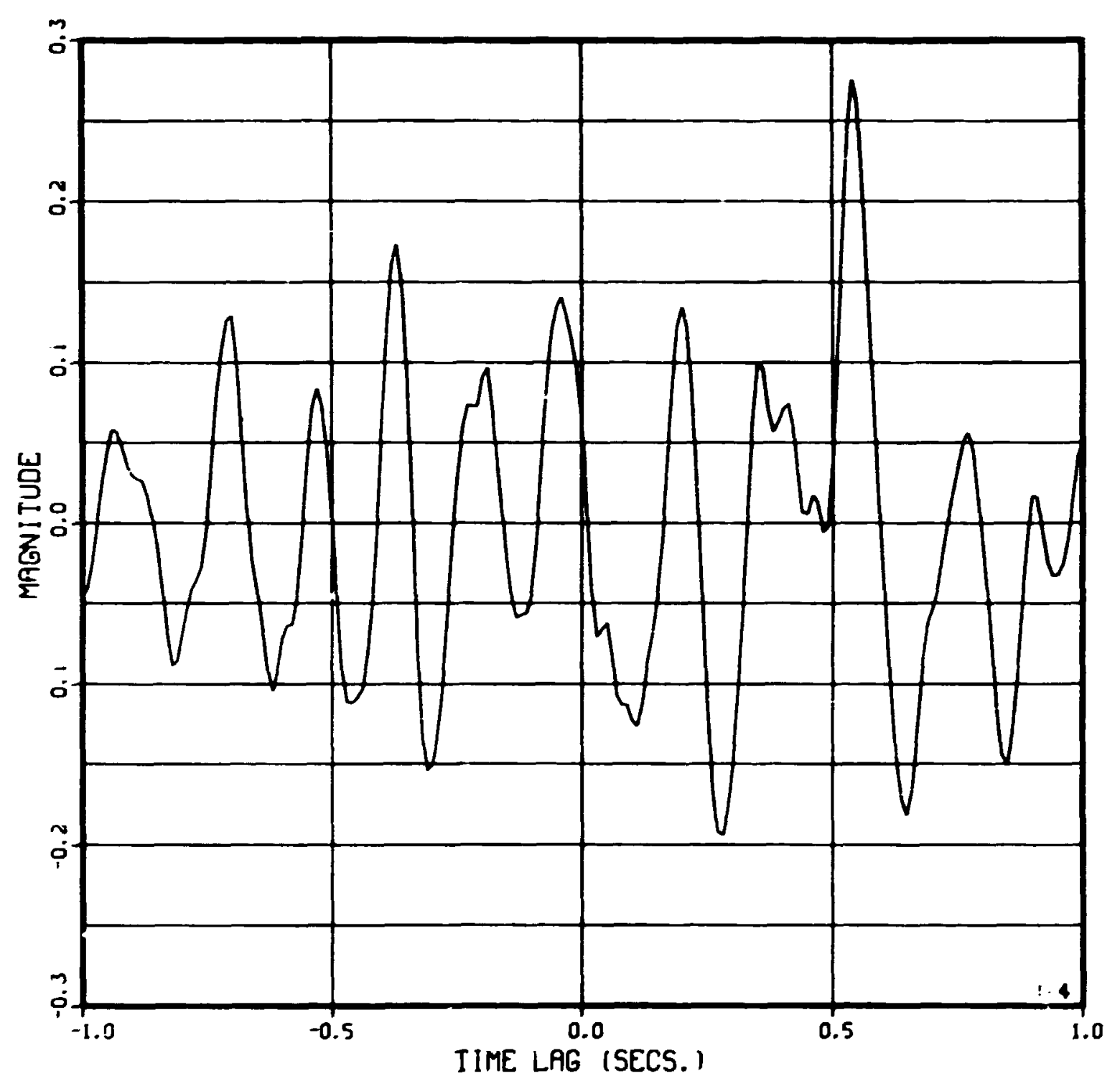

F18. 44. Normalized Cross-Correlation, GATH.02 - GATH.10. 
NORMALIZED CROSS-CORRELATION

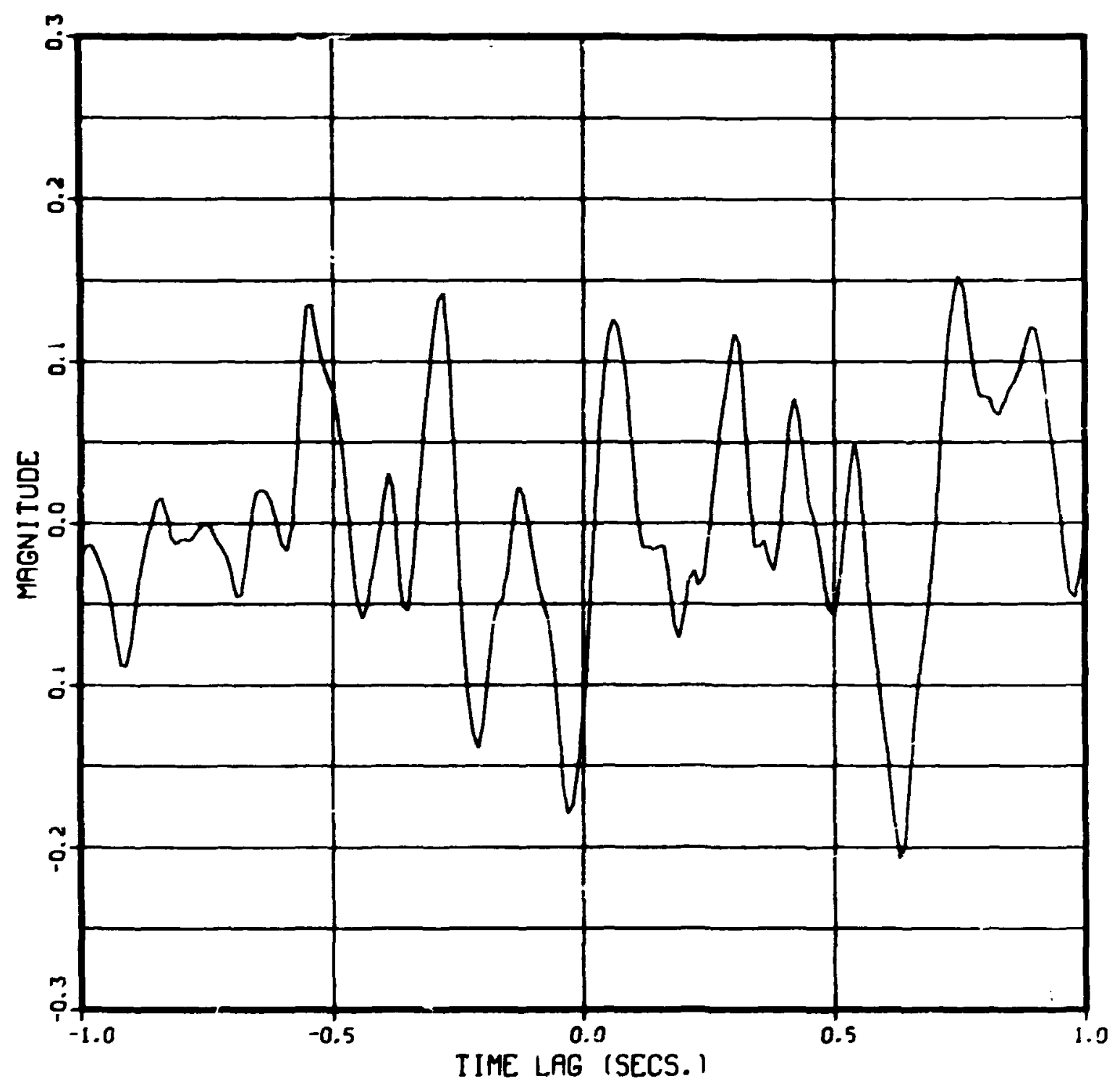

F18. 45. Nermalized Cross-Correlation, GATH.02 - GATH.15. 


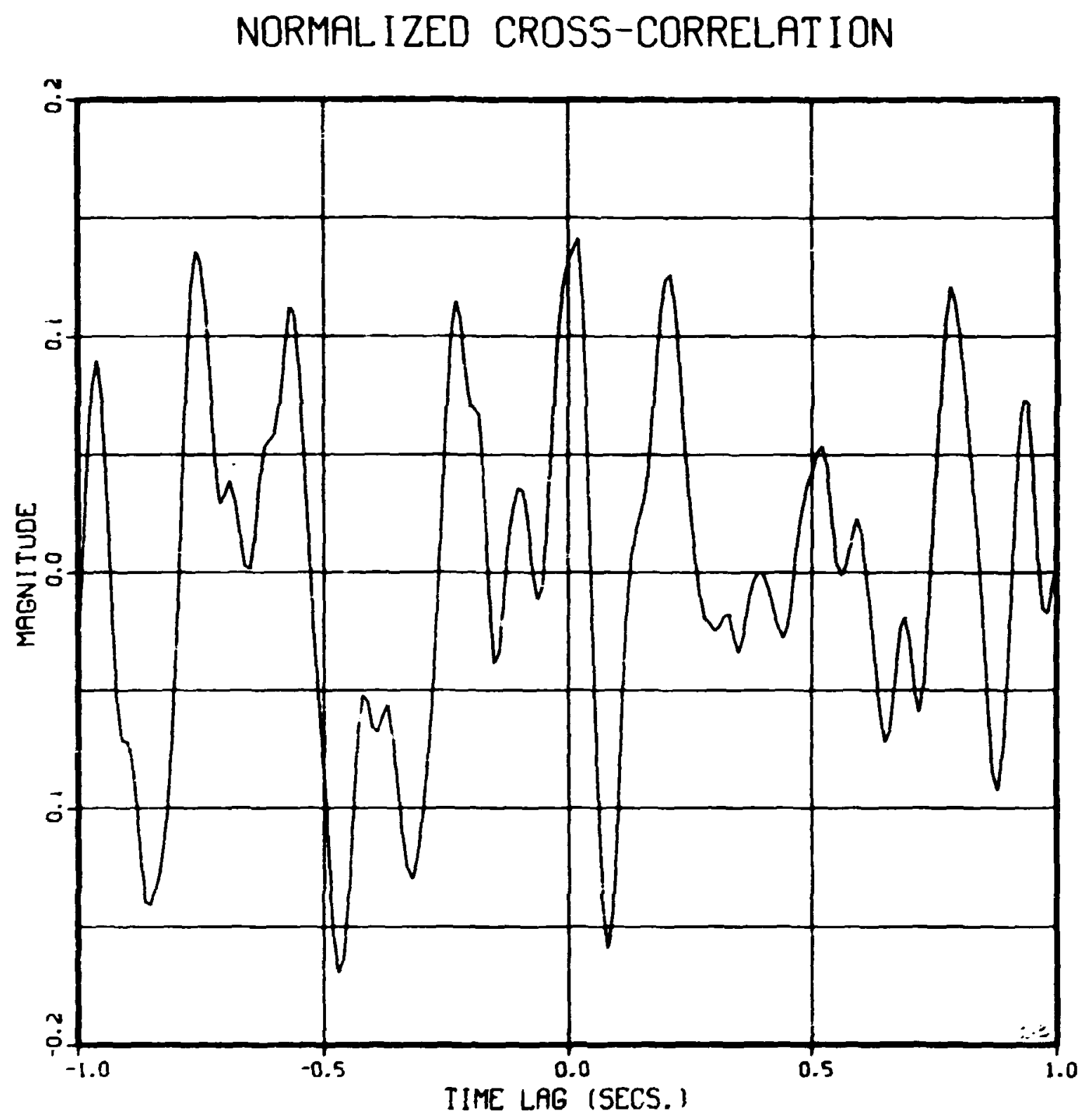

P1g. 46. Normalized Cross-Correlation, GATH.04 - GATH.09. 
NORMAL IZED CROSS-CORRELATION

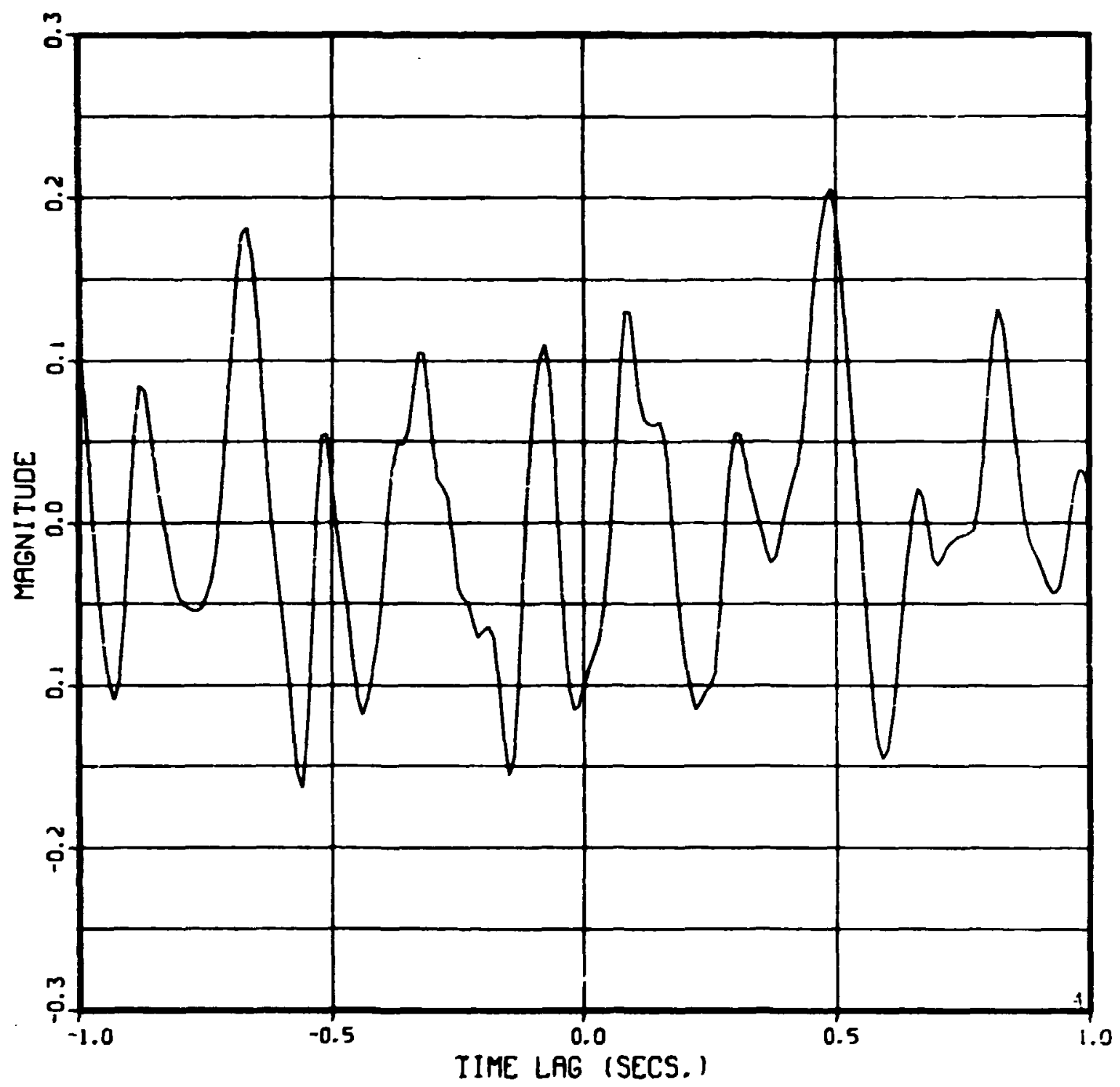

F18. 47. Normalized Cross-Correlation, GATH.04 - GATH.10. 


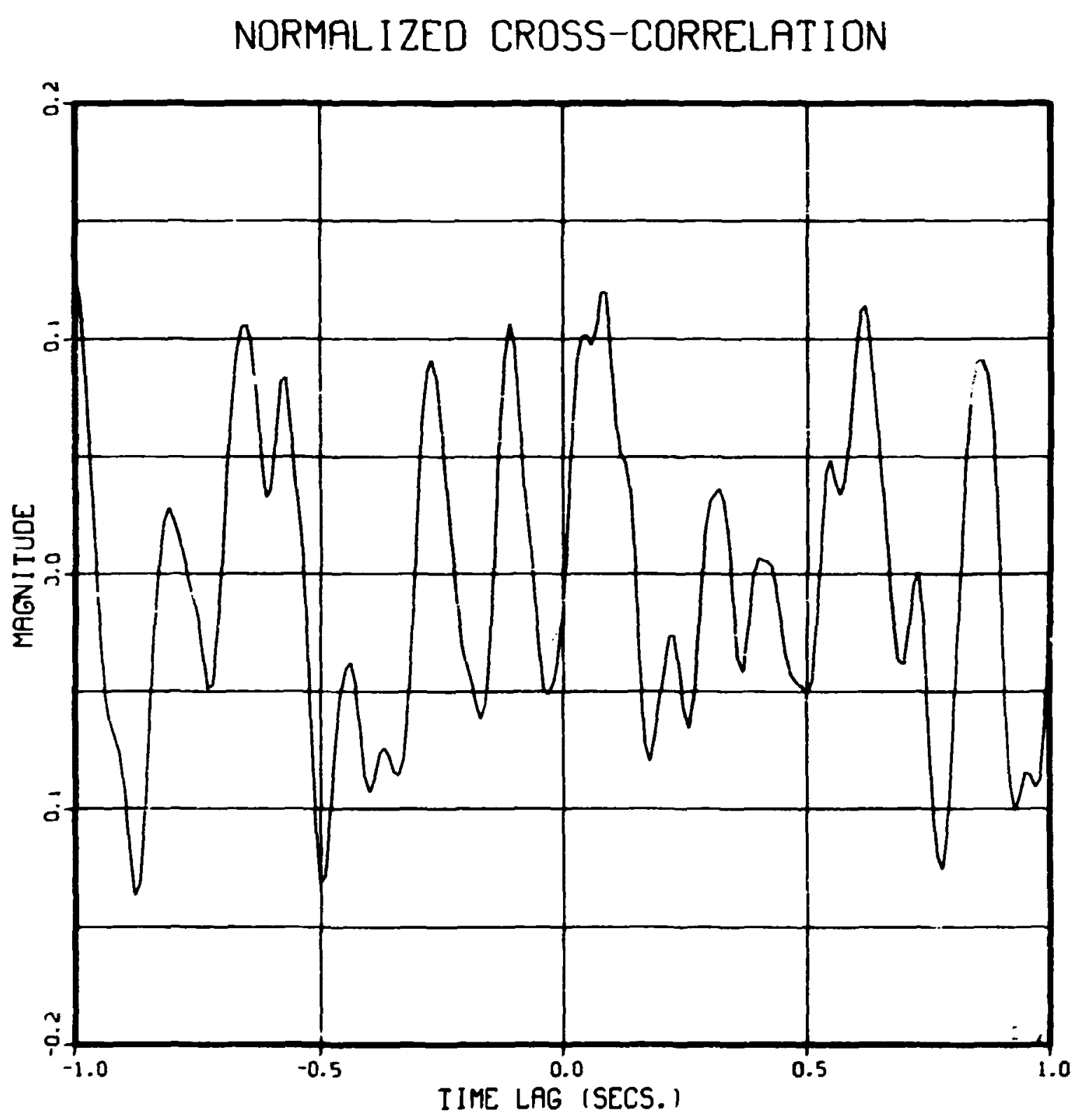

F1g. 48. Normalized Cross-Correlation, GATH.04 - GATH.15. 


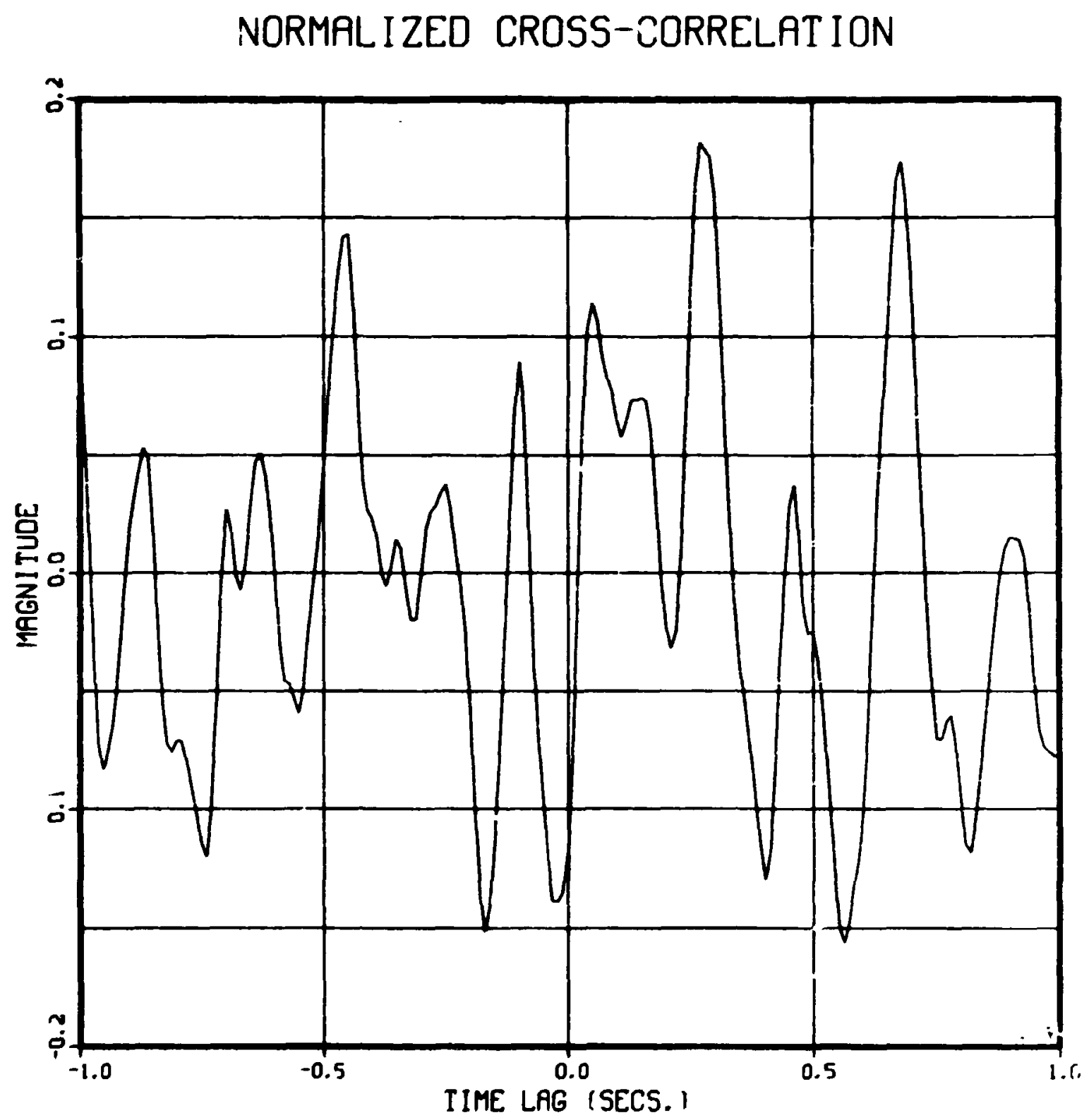

F1g. 49. Normalized Cross-Correlation, GATH.09 - GATH.10. 
NORMALIZEר CROSS-CORRELATION

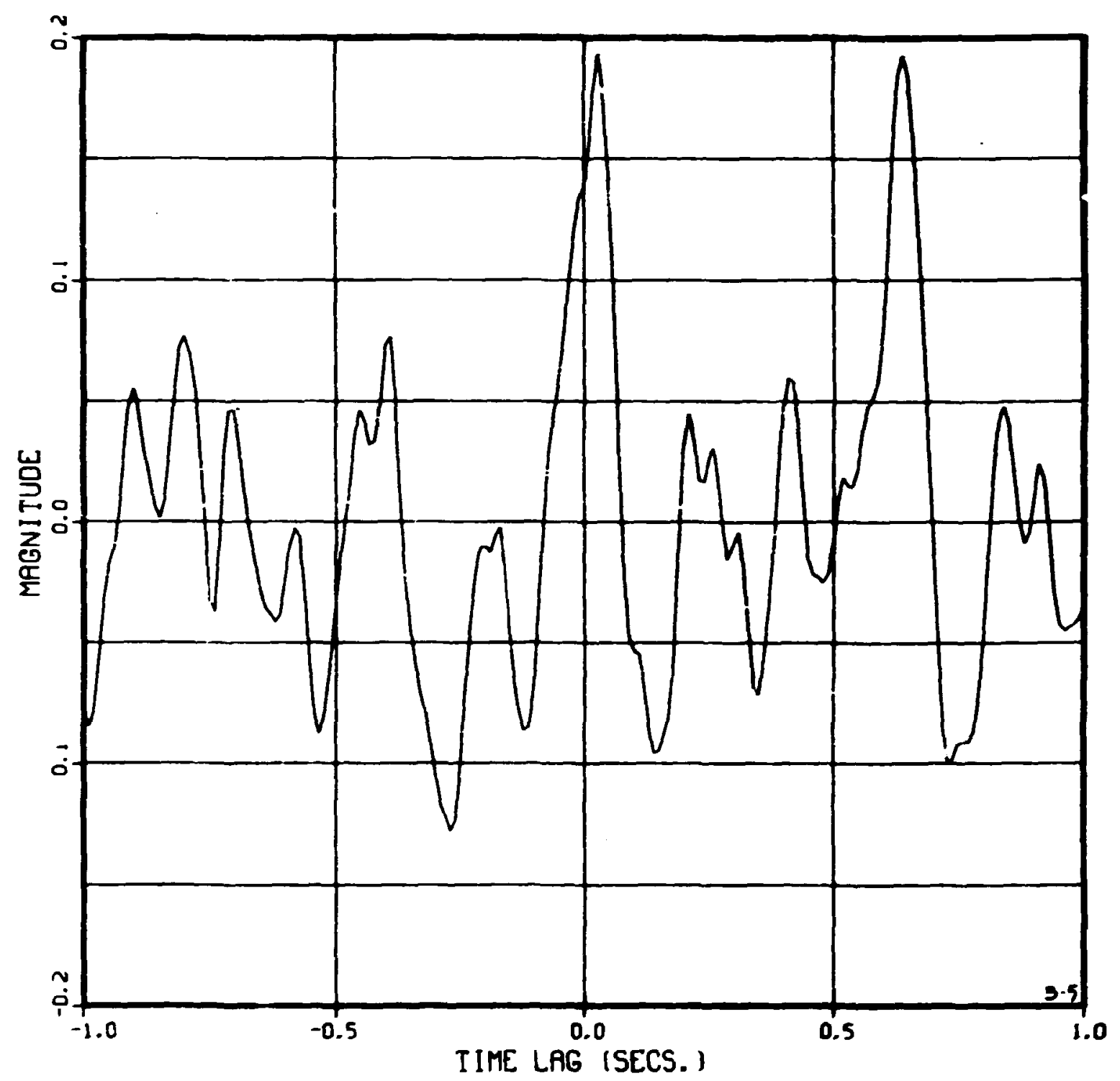

Fig. 50. Normalized Cross-Correlation, GATH.09-GATH.15. 


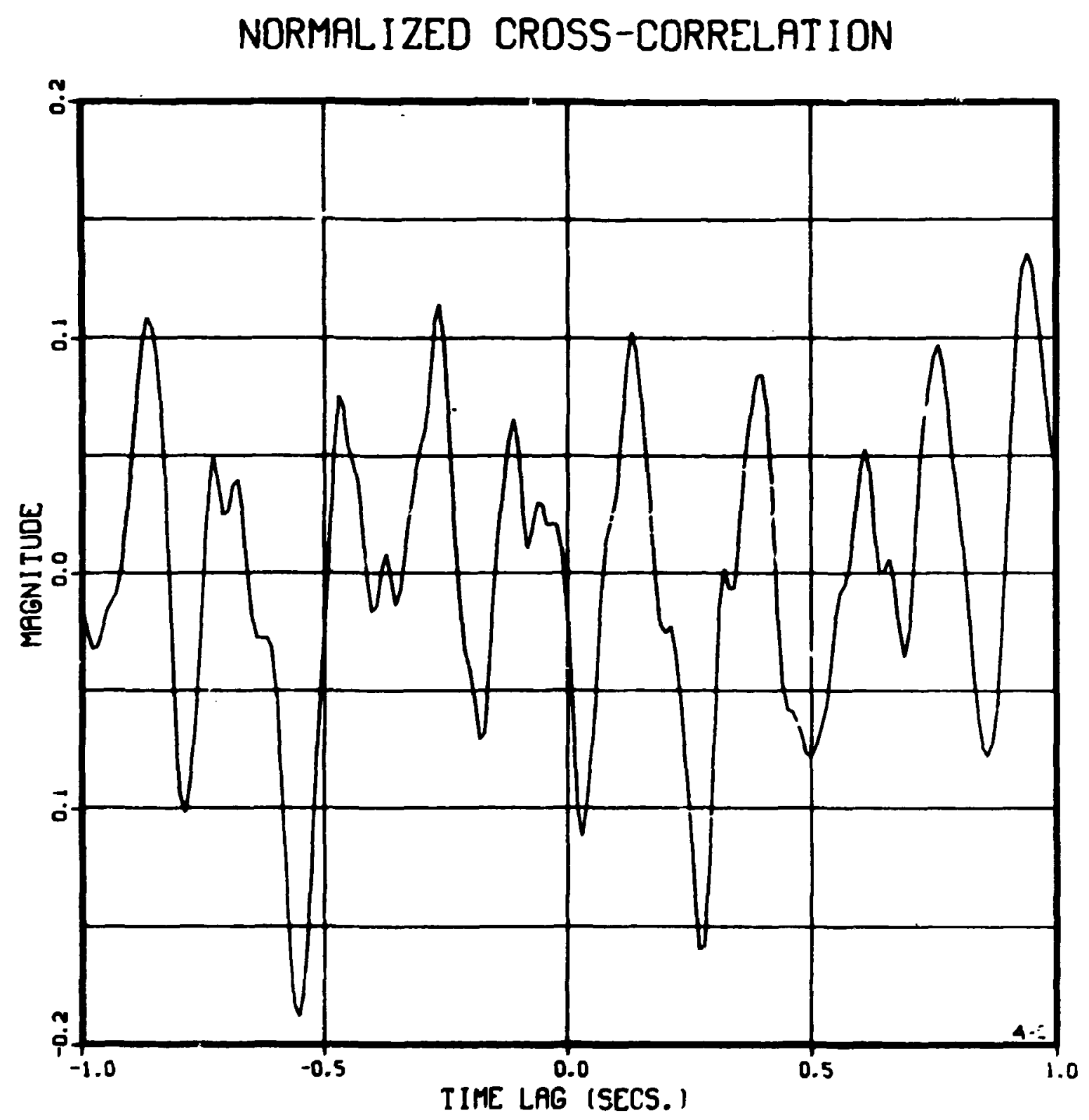

F1g. 51. Normalized Cross-Correlation, GATH.10-GATH.15. 